\title{
Simulations over South Asia using the Weather Research and Forecasting model with Chemistry (WRF-Chem): set-up and meteorological evaluation
}

\author{
R. Kumar ${ }^{1}$, M. Naja ${ }^{1}$, G. G. Pfister ${ }^{2}$, M. C. Barth ${ }^{2}$, and G. P. Brasseur ${ }^{3}$ \\ ${ }^{1}$ Aryabhatta Research Institute of Observational Sciences, Nainital, 263129, India \\ ${ }^{2}$ Atmospheric Chemistry Division, NCAR, Boulder, CO 80307-3000, USA \\ ${ }^{3}$ Climate Service Center, Helmholtz Zentrum Geesthacht, Hamburg 20146, Germany
}

Correspondence to: M. Naja (manish@aries.res.in)

Received: 14 November 2011 - Published in Geosci. Model Dev. Discuss.: 22 November 2011

Revised: 8 February 2012 - Accepted: 21 February 2012 - Published: 20 March 2012

\begin{abstract}
The configuration and evaluation of the meteorology is presented for simulations over the South Asian region using the Weather Research and Forecasting model coupled with Chemistry (WRF-Chem). Temperature, water vapor, dew point temperature, zonal and meridional wind components, precipitation and tropopause pressure are evaluated against radiosonde and satellite-borne (AIRS and TRMM) observations along with NCEP/NCAR reanalysis fields for the year 2008. Chemical fields, with focus on tropospheric ozone, are evaluated in a companion paper. The spatial and temporal variability in meteorological variables is well simulated by the model with temperature, dew point temperature and precipitation showing higher values during sum$\mathrm{mer} / \mathrm{monsoon}$ and lower during winter. The index of agreement for all the parameters is estimated to be greater than 0.6 indicating that WRF-Chem is capable of simulating the variations around the observed mean. The mean bias (MB) and root mean square error (RMSE) in modeled temperature, water vapor and wind components show an increasing tendency with altitude. MB and RMSE values are within $\pm 2 \mathrm{~K}$ and $1-$ $4 \mathrm{~K}$ for temperature, $30 \%$ and $20-65 \%$ for water vapor and $1.6 \mathrm{~m} \mathrm{~s}^{-1}$ and $5.1 \mathrm{~m} \mathrm{~s}^{-1}$ for wind components. The spatiotemporal variability of precipitation is also reproduced reasonably well by the model but the model overestimates precipitation in summer and underestimates precipitation during other seasons. Such a behavior of modeled precipitation is in agreement with previous studies on South Asian monsoon. The comparison with radiosonde observations indicates a relatively better model performance for inland sites as compared to coastal and island sites. The MB and RMSE in tropopause pressure are estimated to be less than $25 \mathrm{hPa}$. Sensitivity simulations show that biases in meteorological
\end{abstract}

simulations can introduce errors of $\pm(10-25 \%)$ in simulations of tropospheric ozone, $\mathrm{CO}$ and $\mathrm{NO}_{\mathrm{x}}$. Nevertheless, a comparison of statistical metrics with benchmarks indicates that the model simulated meteorology is of sufficient quality for use in chemistry simulations.

\section{Introduction}

South Asia is characterized by a widely-varying landscape including the elevated Himalayan terrain, semi-arid and desert land masses, tropical rainforests, sea-shores and the vast plains. This region stretches from Afghanistan and Pakistan in the west to the northeastern provinces of India and Myanmar in the east and is bounded to the north by China and to the south by the Indian Ocean. Apart from this natural landscape diversity, the anthropogenic emissions of trace gases and aerosols are increasing rapidly over this region (e.g. Akimoto, 2003; Ohara et al., 2007). The pollutants emanating from South Asia may have a wide range of potential consequences for the air quality, radiation budget and the atmospheric chemistry on the regional to global scales (e.g. Ramanathan and Crutzen, 2003; Lawrence and Lelieveld, 2010). Further, South Asia is a region of intense photochemical activity due to the availability of strong tropical solar radiation and high humidity.

In light of the above conditions, in situ measurements of different trace species, in particular of ozone and aerosols, have been initiated over the Indian region in the 1990s (e.g. Lal et al., 2000; Babu et al., 2002; Naja and Lal, 2002; Sagar et al., 2004; Jain et al., 2005; Niranjan et al., 2006; Satheesh et al., 2008). In addition, only a few national and 
international campaigns such as the Indian Ocean Experiment (INDOEX) (Ramanathan et al., 2001; Lelieveld et al., 2001) and the Integrated Campaign for Aerosols, gases and Radiation Budget (ICARB) (Moorthy et al., 2008) have been conducted over the adjoining marine regions of the Arabian Sea, Bay of Bengal and Indian Ocean to study the impact of South Asian emissions on the pristine oceanic environments and export of pollutants from this region. Further, a yearlong intensive field campaign (Regional Aerosol Warming Experiment (RAWEX) - Ganges Valley Aerosol Experiment (GVAX) is being carried out over Northern India with ARIES, Nainital as a main site to study the impact of aerosols on cloud formation and precipitation (http://www.arm.gov/ sites/amf/pgh). Although these measurements provide highly valuable information about the diurnal and seasonal variability of trace species they are not sufficient to derive information on the regional distribution of trace gases and aerosols. Due to the scarcity of in situ observations, the additional use of chemical transport models is essential for understanding the spatio-temporal distribution of trace species in this region and their implications on the air quality and climate.

Previous studies have focused on simulating the distribution of ozone and related species over this region using regional (e.g. Roy et al., 2008; Engardt, 2008) and global chemical transport models (e.g. Beig and Brasseur, 2006). However, all these studies used offline models which generally decouple the chemical and meteorological processes by using the output of a standard meteorological model as the input for the chemical model and thus have some inevitable limitations. For instance, these models do not allow feedbacks between the chemistry and meteorology and may miss important information about the short-term atmospheric processes. In this study we employ a fully coupled online regional air quality model known as the "Weather Research and Forecasting model coupled with Chemistry" (WRF-Chem) (Grell et al., 2005). The meteorological and chemical components of the chemistry modules use the same horizontal and vertical coordinates and the same physical parameterization as the meteorological model. The model does not perform any time interpolation and allows the feedback between chemical and meteorological processes (Grell et al., 2005).

Several studies have validated the WRF-Chem model against observations over North America (e.g. McKeen et al., 2005; Tie et al., 2007), Europe (Schürmann et al., 2009) and East Asia (Matsui et al., 2009). However, such efforts have not been made so far over the South Asian region. The WRF model has been employed earlier over the Indian region to study extreme weather events (e.g. Rajeevan et al., 2010; Dutta and Prasad, 2010), the monsoon depressions (e.g. Chang et al., 2009) and to study impact of assimilation schemes on short range forecasts (e.g. Rakesh et al., 2009). These studies indicate that the WRF model has good ability to simulate these events and produces much better forecasts with assimilated fields. However, these studies did not provide information on the skill of WRF in simulating the year-long meteorology of this region. Therefore, this study is aimed at evaluation and quantification of errors and biases in WRF-Chem simulated meteorological fields over the course of all seasons and impact of meteorological errors on chemistry simulations with focus on tropospheric ozone. Such evaluation is essential to establish the model's credibility for future studies. In this manuscript, the meteorological fields simulated by the WRF-Chem model are evaluated against a set of balloon-borne and space-borne observations and reanalysis datasets. The evaluation of chemical fields is discussed in another manuscript (Kumar et al., 2012).

Ground-based observations are amongst the most accurate and reliable dataset for evaluating the model performance in regard to air quality but these measurements have limited geographical and altitude coverage over the Indian region and are highly sparse over the remote oceanic and mountainous regions. This spatial heterogeneity in the availability of in situ observations might lead to a sampling bias in the model evaluation. The gap in spatial heterogeneity can be minimized to a large extent by the use of satellite observations and reanalysis datasets. The satellites provide daily global three dimensional observations of the atmospheric state while the reanalysis datasets are generated by the quality controlled assimilation of observations from different platforms such as from land, ship, aircraft, radiosonde and pibal (pilot balloon) etc.

In this study, we used temperature and dew point temperature from radiosonde observations, temperature, water vapor and tropopause pressure retrieved by the atmospheric infrared sounder (AIRS), daily total precipitation amounts from the Tropical Rainfall Measuring Mission (TRMM), as well as NCEP/NCAR reanalysis zonal and meridional wind components for the evaluation of WRF-Chem meteorological fields. The outline of the manuscript is as follows. We first give a description of the WRF-Chem model configuration in Sect. 2. The information on different observational datasets, the reanalysis fields and the evaluation methodology used in this study are presented in Sect. 3. The evaluation and sensitivity results are described in Sect. 4 and are summarized in Sect. 5.

\section{The model description}

This study uses version 3.1.1 of the fully compressible and non-hydrostatic Advanced Research WRF model (http: //www.mmm.ucar.edu/wrf/users/) coupled with Chemistry (WRF-Chem; http://ruc.fsl.noaa.gov/wrf/WG11) developed jointly by NOAA, DOE/PNNL, NCAR and other research institutes. The WRF model (Skamarock et al., 2008) uses the terrain-following hydrostatic pressure as the vertical coordinate and Arakawa-C grid for grid staggering. The model uses the Runge-Kutta second and third order time integration schemes and second to sixth order advection schemes in both the horizontal and vertical directions. A time-split small step 


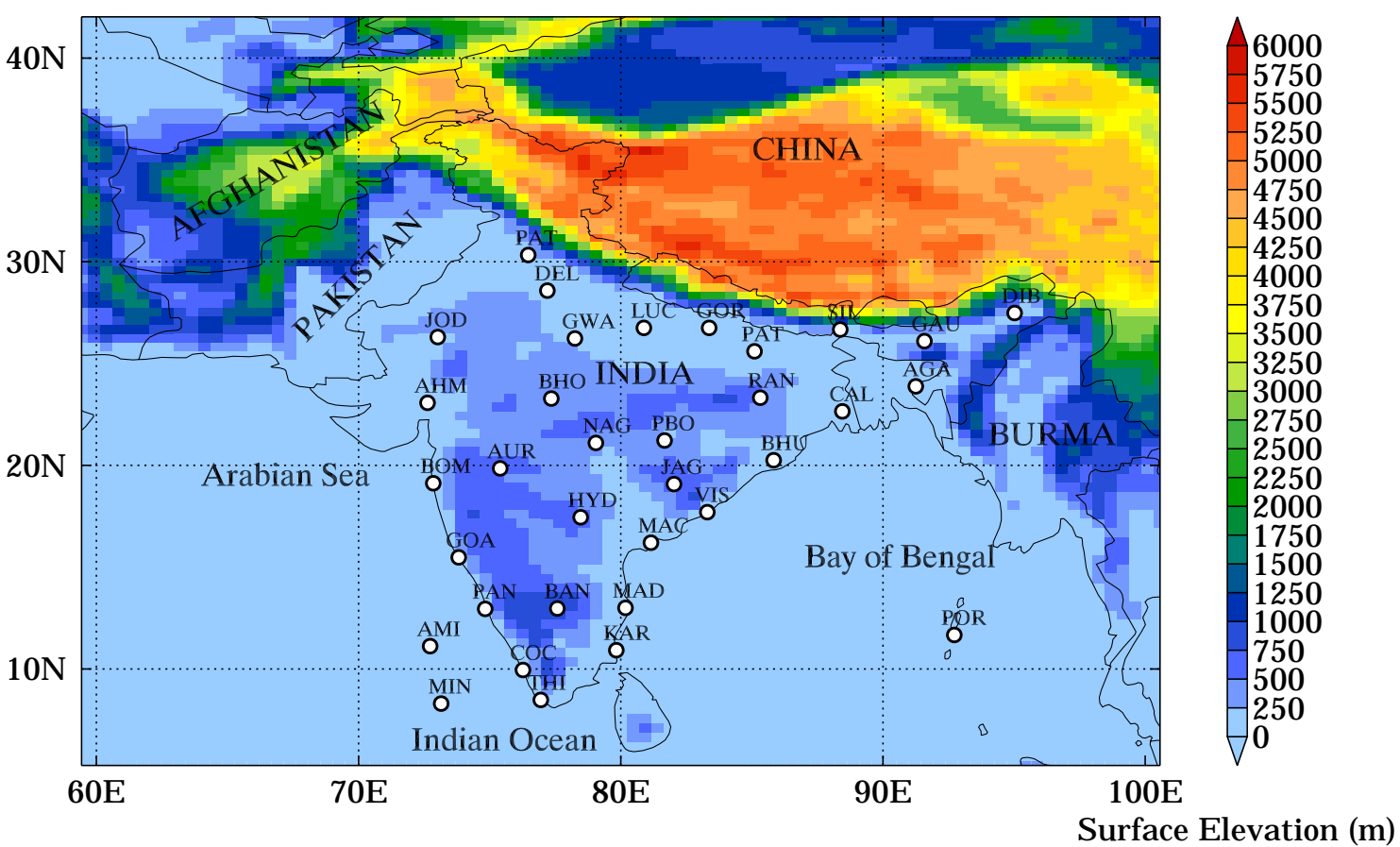

Fig. 1. The simulation domain and the topography used by the model. The geographic locations of RAOB sites used in this study are also shown. The description of station codes is provided in Table 1.

scheme is used for an acoustic and gravity-wave model. In this study, the simulation domain is defined on the Mercator projection centered at $25^{\circ} \mathrm{N}, 80^{\circ} \mathrm{E}$ (Fig. 1). The domain covers nearly the entire South Asian region with a $45 \mathrm{~km}$ spatial resolution and has 90 grid points in both the west-east and the north-south directions. The $45 \mathrm{~km}$ resolution is chosen because the fine-scale anthropogenic emissions data are available at $0.5^{\circ}$ resolution, which limits the model resolution. There are 51 vertical levels in the model from the surface to $\sim 30 \mathrm{~km}(10 \mathrm{hPa}), 10$ of which are located within $1 \mathrm{~km}$ above the model surface. The model top is placed at $10 \mathrm{hPa}$ because modeled vertical ozone distribution showed better agreement with observations with higher $(10 \mathrm{hPa})$ model top as compared to lower $(50 \mathrm{hPa})$ model top.

The static geographical fields such as the terrain height, land-use/vegetation, soil properties, vegetation fraction and albedo etc. are interpolated from $10 \mathrm{~min}$ (approximately $19 \mathrm{~km}$ ) United States Geological Survey (USGS) data to the simulation domain by using the geogrid program of the WRF preprocessing system (WPS). The surface terrain (Fig. 1) used by the model has an important influence on the meteorology and chemical distributions. The northern part of South Asia with the Himalaya Mountains has a montane and temperate climate, while the southern part is surrounded by oceans and experiences a mostly moist climate. The driest weather prevails in the Great Indian Thar Desert $\left(\sim 24^{\circ}-\right.$ $\left.30^{\circ} \mathrm{N} ; \sim 70^{\circ}-75^{\circ} \mathrm{E}\right)$ in western India. Forested regions are generally found at high altitude and high rainfall regions in northern, north-eastern and southern parts of India. Further details regarding the topographical features, land-use and classification patterns in India can be found on the website of the Ministry of Environment and Forests, Government of India (http://moef.nic.in/index.php). The initial and lateral boundary conditions for meteorological parameters are obtained from NCEP Final analysis (FNL) fields available every $6 \mathrm{~h}$ at the spatial resolution of $1^{\circ} \times 1^{\circ}$.

The resolved-scale cloud physics is represented by the Thompson microphysics scheme (Thompson et al., 2004), which includes seven moisture variables undergoing liquidphase, ice-phase and mixed-phase processes. The sub-grid scale effects of convective and shallow clouds are parameterized according to the Kain-Fritsch convective scheme (Kain, 2004). The Rapid Radiative Transfer Model (RRTM) long-wave radiation scheme (Mlawer et al., 1997) is used to represent long-wave radiative processes due to water vapor, clouds and trace gases (e.g. $\mathrm{CO}_{2}$, ozone etc.). The shortwave radiative processes are incorporated using the Goddard short-wave scheme (Chou and Suarez, 1994). The feedback from the aerosols to the radiation scheme has been turned on in the simulation. The aerosol module used here is based on the Modal Aerosol Dynamics Model for Europe/Secondary Organic Aerosol Model (MADE/SORGAM) (Ackermann et al., 1998; Schell et al., 2001) and dust emissions are calculated online within the model using landscape and meteorological information. The friction velocities and exchange coefficients that enable the calculation of surface thermal and moisture fluxes by land-surface model and surface stress in the planetary boundary layer scheme 
Table 1. Details and the categorization of the RAOB sites used in this study.

\begin{tabular}{|c|c|c|c|c|c|c|}
\hline $\begin{array}{l}\text { Station } \\
\text { Name }\end{array}$ & $\begin{array}{l}\text { Station } \\
\text { Code }\end{array}$ & $\begin{array}{r}\text { Longitude } \\
\left({ }^{\circ} \mathrm{E}\right)\end{array}$ & $\begin{array}{l}\text { Latitude } \\
\qquad\left({ }^{\circ} \mathrm{N}\right)\end{array}$ & $\begin{array}{r}\text { Actual } \\
\text { Altitude* }\end{array}$ & $\begin{array}{r}\text { Model } \\
\text { Altitude* }\end{array}$ & Category \\
\hline Bhubaneswar & $\mathrm{BHU}$ & 85.83 & 20.25 & 46 & 47 & \multirow{10}{*}{ Coastal Sites } \\
\hline Bombay & BOM & 72.85 & 19.12 & 14 & 42 & \\
\hline Machilipatnam & MAC & 81.15 & 16.20 & 3 & 3 & \\
\hline Goa/Panjim & GOA & 73.82 & 15.48 & 60 & 120 & \\
\hline Madras & MAD & 80.18 & 13.00 & 16 & 22 & \\
\hline Panambur & PAN & 74.83 & 12.95 & 31 & 45 & \\
\hline Vishakhapatnam & VIS & 83.30 & 17.70 & 66 & 54 & \\
\hline Thiruvanantpuram & THI & 76.95 & 8.48 & 64 & 100 & \\
\hline Karaikal & KAR & 79.83 & 10.92 & 7 & 3 & \\
\hline Cochin & $\mathrm{COC}$ & 76.27 & 9.95 & 3 & 15 & \\
\hline Port-Blair & POR & 92.72 & 11.67 & 79 & 8 & \multirow{3}{*}{ Island Sites } \\
\hline Minicoy-Island & MIN & 73.15 & 8.30 & 2 & 0 & \\
\hline Amini-Divi & AMI & 72.73 & 11.12 & 4 & 0 & \\
\hline Patiala & PAT & 76.47 & 30.33 & 251 & 245 & \multirow{15}{*}{ Low Altitude Sites } \\
\hline Delhi & DEL & 77.20 & 28.58 & 216 & 213 & \\
\hline Dibrugarh & DIB & 95.02 & 27.48 & 111 & 57 & \\
\hline Jodhpur & JOD & 73.02 & 26.30 & 224 & 225 & \\
\hline Gwalior & GWA & 78.25 & 26.23 & 207 & 191 & \\
\hline Lucknow & LUC & 80.88 & 26.75 & 128 & 123 & \\
\hline Gorakhpur & GOR & 83.37 & 26.75 & 77 & 64 & \\
\hline Siliguri & SIL & 88.37 & 26.67 & 123 & 224 & \\
\hline Gauhati & GAU & 91.58 & 26.10 & 54 & 298 & \\
\hline Patna & PAT & 85.10 & 25.60 & 60 & 45 & \\
\hline Ahmedabad & AHM & 72.63 & 23.07 & 55 & 54 & \\
\hline Raipur & RAI & 81.67 & 21.22 & 298 & 283 & \\
\hline Nagpur & NAG & 79.05 & 21.10 & 310 & 322 & \\
\hline Agartala & AGA & 91.25 & 23.88 & 16 & 25 & \\
\hline Calcutta & CAL & 88.45 & 22.65 & 6 & 6 & \\
\hline Aurangabad & AUR & 75.40 & 19.85 & 579 & 559 & \multirow{6}{*}{$\begin{array}{l}\text { Moderately High } \\
\text { Altitude Sites }\end{array}$} \\
\hline Bhopal & $\mathrm{BHO}$ & 77.35 & 23.28 & 523 & 467 & \\
\hline Ranchi & RAN & 85.32 & 23.32 & 652 & 502 & \\
\hline Jagdalpur & JAG & 82.03 & 19.08 & 553 & 564 & \\
\hline Hyderabad & HYD & 78.47 & 17.45 & 545 & 537 & \\
\hline Bangalore & BAN & 77.58 & 12.97 & 921 & 853 & \\
\hline
\end{tabular}

* The altitude values are in meters above mean sea level (a.m.s.l.).

are calculated according to Monin-Obukhov similarity theory using the Eta surface layer scheme (Janjic, 1996). The unified Noah land-surface model (Chen and Dudhia, 2001), using USGS $1 \mathrm{~km}$ land-surface data is used to obtain thermal and moisture fluxes from the surface. The vertical sub-grid scale fluxes due to eddy transports in the planetary boundary layer and the free atmosphere are parameterized according to the Mellor-Yamada-Janjic (MYJ) boundary layer scheme (Janjic, 1996, 2002). Further details of the different kinds of emissions (anthropogenic, biomass burning and biogenic) of trace gases and aerosols, and the chemical mechanism used by the model are provided in Kumar et al. (2012).
Twelve 1-month simulations are conducted for January to December 2008. The model is reinitialized at 00:00 UTC on the first date of every month and four dimensional data assimilation (FDDA) technique is applied to limit the model errors in simulated meteorological fields (e.g. Lo et al., 2008). The horizontal winds, moisture and temperature are nudged at all vertical levels with a nudging coefficient of $6 \times 10^{-4}$. The time-step of the model simulation is taken as $180 \mathrm{sec}$ onds $(4 \times$ grid spacing) to ensure that the model does not violate the Courant-Friedrichs-Levy (CFL) stability criterion (Courant et al., 1928). The radiation physics modules are called every $540 \mathrm{~s}$ while the modules for boundary layer and cumulus physics are called every time step. The instantaneous model results are outputted every hour. 


\section{Datasets and evaluation methodology}

\subsection{Radiosonde observations}

The radiosonde observations (RAOB) of temperature and dew point temperature at 12 mandatory pressure levels $(1000 \mathrm{hPa}, 925 \mathrm{hPa}, 850 \mathrm{hPa}, 700 \mathrm{hPa}, 600 \mathrm{hPa}, 500 \mathrm{hPa}$, $400 \mathrm{hPa}, 300 \mathrm{hPa}, 250 \mathrm{hPa}, 200 \mathrm{hPa}, 150 \mathrm{hPa}$ and $100 \mathrm{hPa}$ ) for 34 stations located in the Indian region are used for the evaluation. Table 1 provides the details of all the RAOB stations used in this study and the geographical locations of these stations are shown in Fig. 1. These observations are generally carried out around 00:00 and 12:00 UTC each day and are quality checked for the climatological limits as described by Schwartz and Govett (1992) prior to their archival. Several studies have used the RAOB datasets for validating satellite retrievals (e.g. Remsberg et al., 1992; Divakarla et al., 2006). Here, the RAOB sites over the Indian region are classified into four categories namely coastal, island, low altitude and moderately high altitude sites depending upon the surrounding landscape and the altitude. The sites located along the eastern and western coasts of India are classified as "coastal sites" while those located on the islands are termed as "island sites". All other sites having altitudes between 0 $500 \mathrm{~m}$ and $500-1000 \mathrm{~m}$ are classified as "low altitude" and "moderately high altitude" sites, respectively.

\subsection{Satellite-borne observations}

We use data products from the Atmospheric Infrared Sounder (AIRS) aboard the Aqua satellite and Tropical Rainfall Measuring Mission (TRMM) for model evaluation. AIRS is a high resolution infrared spectrometer accompanied by the Advanced Microwave Sounding Unit (AMSU) and Humidity Sounder for Brazil (HSB) (Aumann et al., 2003). AIRS has a field of view of $1.1^{\circ}$ and measures the Earth's radiance in the 3.74-15.4 $\mu \mathrm{m}$ wavelength range. The horizontal resolution is $\sim 45 \mathrm{~km}$ and the vertical resolution in the troposphere is $\sim 1 \mathrm{~km}$ for temperature and $\sim 2 \mathrm{~km}$ for water vapor. The AIRS temperature and water vapor retrievals have been successfully validated against a variety of in situ and aircraft observations (e.g. Gettelman et al., 2004; Divakarla et al., 2006). These validation studies show that the accuracy of AIRS retrievals is about $1 \mathrm{~K}$ in $1 \mathrm{~km}$ layers for temperature and is better than $15 \%$ in $2 \mathrm{~km}$ layers for water vapor. All the AIRS datasets used in this study are version-5 Level-2 standard products.

The Tropical Rainfall Monitoring Mission (TRMM) is a multi-sensor instrument, which uses the space-borne observations to adjust the geosynchronous infrared satellite data and provide the gridded precipitation amounts at a range of spatial and temporal resolutions (Adler et al., 2000). We use daily total precipitation amount at spatial resolution of $0.25^{\circ} \times 0.25^{\circ}$ corresponding to $3 \mathrm{~B} 42$ algorithm of the TRMM. The 3B42 algorithm produces the infrared calibration parameters from the measured radiances, which are then used to adjust the merged-infrared precipitation data (http://trmm.jpl.nasa.gov). The TRMM 3B42 precipitation data products are shown to accurately reproduce the climatology and rainfall variability over the Indian region (Nair et al., 2009) and have been used previously for the evaluation of WRF simulated rainfall over this region (e.g. Rakesh et al., 2009).

\subsection{Reanalysis dataset}

The NCEP/NCAR reanalysis datasets generated by the assimilation of quality controlled ground-based, ship-based, air-borne and space-borne meteorological observations into a state-of-the-art global data assimilation system (Kalnay et al., 1996; Kistler et al., 2001) are also used here for the model evaluation. These datasets have been widely used by the atmospheric research community for providing input to several regional and global models, transport models and for understanding various research problems of scientific interest (e.g. Rao et al., 1998; Hashiguchi et al., 2006). In this study, we have used the NCEP/NCAR reanalysis $U$ and $V$ wind components for evaluating the WRF simulated wind components. These NCEP/NCAR wind components are available 4 times (00:00, 06:00, 12:00 and 18:00 GMT) daily at the spatial resolution of $2.5^{\circ}$ and at 17 pressure levels between 1000 and $10 \mathrm{hPa}$.

\subsection{Evaluation methodology}

The model predicted value is matched with the observed fields (RAOB/satellite retrieval/reanalysis data location) in space and time and paired values are stored for further analysis. The spatial matching between the model and observations is achieved in two steps. First, the grid index $(i, j)$ corresponding to the geographical location of the observation site is determined. In the second step, the model value at the estimated grid index $(i, j)$ is calculated from the surrounding four model grid points by bi-linear interpolation. The temporal matching is obtained by averaging the WRF-Chem output over the hours enclosing the time of observation. To assure the quality of RAOB datasets, all the observations in the monthly datasets outside the range of $2 \sigma$ (standard deviation) around the mean are excluded from the further analysis.

The best quality AIRS retrievals are obtained for the model evaluation by selecting clear sky AIRS temperature and water vapor retrievals corresponding to highest quality assurance flags as suggested by AIRS science team. The quality assurance flags also allow discrimination of erroneous retrievals above a certain height and thus total number of samples accepted at different pressure levels is not the same. We select for clear sky retrievals only, and hence the total number of samples accepted at any pressure level in summer is even smaller (30-90\%) than those in any other season because of the frequent occurrence of cloudy conditions in summer over 
the South Asian region. The water vapor profiles for which the estimated error in the retrieved value is either negative or greater than $50 \%$ of the retrieved value are also rejected. Complete description of these quality assurance flags are provided in Olsen et al. (2007). The temperature and water vapor profiles in AIRS retrievals are reported as layer average quantities. Hence, layer average WRF-Chem profiles are also calculated by averaging all the model data lying between any two consecutive AIRS pressure levels.

\subsection{Statistical metrics}

This section defines different statistical metrics used for evaluating the model performance and quantifying the errors in model simulated meteorological variables. These include the mean bias (MB), coefficient of determination $\left(r^{2}\right)$, root mean square error (RMSE), the systematic and unsystematic root mean square errors $\left(\mathrm{RMSE}_{\mathrm{s}}\right.$ and $\mathrm{RMSE}_{\mathrm{u}}$ ) and the index of agreement $(d)$ (Willmott, 1981). The mean bias provides the information on the overestimation/underestimation of any variable by the model and is defined as:

$\mathrm{MB}=\frac{1}{N} \sum_{i=0}^{N}\left(O_{i}-M_{i}\right)$

In Eq. (1), the summations are performed over the total number of model-observations pair values $(N)$ while $O_{i}$ and $M_{i}$ represent the $i$-th observed and modeled values, respectively. The coefficient of determination $\left(r^{2}\right)$ tells about the strength of linear relationship between model and observations and is represented simply by the square of Person's product moment correlation coefficient $(r)$, which is calculated as:

$r=\left[\frac{\sum_{i=0}^{N}\left(O_{i}-\bar{O}\right)\left(M_{i}-\bar{M}\right)}{\sqrt{\sum_{i=0}^{N}\left(O_{i}-\bar{O}\right)^{2} \sum_{i=1}^{N}\left(M_{i}-\bar{M}\right)^{2}}}\right]$

In Eq. (2), the over bars over $O$ and $M$ indicate the average values in the observation and model. The index of agreement $(d)$, which determines the model skill in predicting the variations about the observed mean, is calculated as:

$d=1-\frac{N \cdot \mathrm{RMSE}^{2}}{\sum_{i=1}^{N}\left(\left|O_{i}-\bar{O}\right|+\left|M_{i}-\bar{O}\right|\right)^{2}}$

Both $d$ and $r^{2}$ are dimensionless statistical quantities and vary between 0 (no agreement between model and observations) and 1 (perfect agreement). The RMSE considers error compensation due to opposite sign differences and is calculated as

$\mathrm{RMSE}=\sqrt{\frac{\sum_{i=1}^{N}\left(O_{i}-M_{i}\right)^{2}}{N}}$

Although RMSE encapsulates the average error produced by the model but it does not illuminate the sources or the
Table 2. Different symbols used in calculation of the hit rate statistics.

\begin{tabular}{lccc}
\hline & & \multicolumn{2}{c}{$\begin{array}{c}\text { Precipitation Observed } \\
\text { by TRMM }\end{array}$} \\
\cline { 3 - 4 } & & Yes & No \\
\hline Precipitation simulated & Yes & $A$ & $B$ \\
by WRF-Chem & No & $C$ & $D$ \\
\hline
\end{tabular}

types of errors. Thus, it is helpful to define a systematic $\left(\mathrm{RMSE}_{\mathrm{s}}\right)$ and unsystematic $\left(\mathrm{RMSE}_{\mathrm{u}}\right)$ component of RMSE. Both of these components are related to the RMSE through the relation:

$\mathrm{RMSE}^{2}=\mathrm{RMSE}_{\mathrm{s}}^{2}+\mathrm{RMSE}_{\mathrm{u}}^{2}$

The unsystematic component $\left(\mathrm{RMSE}_{\mathrm{u}}\right)$ is calculated as:

$\operatorname{RMSE}_{\mathrm{u}}=\sqrt{\left(1-r^{2}\right) \sigma_{\mathrm{m}}^{2}}$

In Eq. (6), $r^{2}$ and $\sigma_{\mathrm{m}}^{2}$ represent the coefficient of determination and the variance of modeled values respectively. Once $\mathrm{RMSE}_{\mathrm{u}}$ is estimated, RMSE $\mathrm{s}_{\mathrm{s}}$ is estimated through Eq. (5).

In addition, five hit rate statistical parameters, the Probability of Detection (POD), False Alarm Rate (FAR), Frequency Bias (FBI), Hansen-Kuipers score (HKS) and Odds Ratios (ORT) are calculated (Stephenson, 2000) to evaluate model simulated precipitation. Hit rate statistics is calculated using the symbolic representation shown in Table 2 . The symbols " $A$ ", " $B$ ", " $C$ " and " $D$ " represents the correct hits, false hits, false rejections and correct rejections, respectively. The probability of detection (POD), which is a measure of the model skill in simulating the observed precipitation, is estimated as:

$\mathrm{POD}=\frac{A}{A+C}$

The relative number of times when the model simulated the precipitation but it did not occur is given by the False Alarm Rate (FAR) defined below:

$\mathrm{FAR}=\frac{B}{B+D}$

To identify whether the model overestimates or underestimates the observed precipitation, frequency bias (FBI) is calculated as follows:

$\mathrm{FBI}=\frac{A+C}{A+B}$

The value of FBI should be unity for a perfect forecasting system but generally differs from unity due to presence of systematic biases in the model or the observations. FBI values less (greater) than 1 indicate the overestimation (underestimation) of precipitation by the WRF. The ability 
of the model to correctly simulate the observed precipitation while avoiding the false alarm rates is assessed using Hansen-Kuipers score (HKS), which is estimated as:

$\mathrm{HKS}=\frac{A D-B C}{(A+C)(B+D)}$

The odd ratios (ORT) provide another measure of evaluating the model skills by weighting the probability of occurrence of the event with the probability of non-occurrence of the event.

$\mathrm{ORT}=\frac{A D}{B C}$

The ORT values greater than 1 indicates that $\mathrm{POD}>$ FAR and vice-versa.

\section{Results of model evaluation}

The spatial distributions of the model simulated average surface pressure, $2 \mathrm{~m}$ temperature, $2 \mathrm{~m}$ water vapor and the total precipitation over the model domain during the four seasons winter (DJF), spring (MAM), summer (JJA) and autumn (SON) of the year 2008 are depicted in Fig. 2. The surface pressure does not show significant seasonal variability except over some regions in Central and Northern India. In contrast, other parameters i.e. temperature, water vapor and precipitation show a distinct seasonal cycle with the highest values in summer and the lowest values in winter. Highest temperatures are seen in summer over Western India encompassing the desert land masses. Temperature and water vapor do not show significant changes from spring to autumn over the oceanic region of Bay of Bengal. The magnitude of seasonal variations in temperature and water vapor is higher for the regions located north of the $20^{\circ} \mathrm{N}$ latitude belt as compared to the regions located south of this belt. The temperature changes by $25-30 \mathrm{~K}$ during a seasonal cycle in the regions northward of $20^{\circ} \mathrm{N}$ while only by $10-15 \mathrm{~K}$ in the regions southward of $20^{\circ} \mathrm{N}$. The north-south gradient in $2 \mathrm{~m}$ temperature is most prominent during winter. The gradient is also seen during autumn but it is smaller and is within $5 \mathrm{~K}$. Similarly, average water vapor changes by $10-15 \mathrm{~g} \mathrm{~kg}^{-1}$ and $5-10 \mathrm{~g} \mathrm{~kg}^{-1}$ in the northern and southern regions, respectively. This spatial and temporal variability in both temperature and water vapor can be attributed to the differential heating and natural landscape diversity (e.g. Southern parts of the domain are covered largely by the oceans) across the model domain along with the seasonal changes in the regional meteorology. Analysis of modeled solar radiation at the surface shows a stronger seasonal cycle over regions north of $20^{\circ} \mathrm{N}$ with a seasonal amplitude of $300-400 \mathrm{~W} \mathrm{~m}^{-2}$ as compared to $200-250 \mathrm{~W} \mathrm{~m}^{-2}$ over regions south of $20^{\circ} \mathrm{N}$.

Maximum precipitation is simulated during summer when rainfall is abundant over the Indian landmass region. Model simulated rainfall exceeds $1400 \mathrm{~mm}$ over the IGP region, Himalayan foothills and the Western Indian coast in summer.
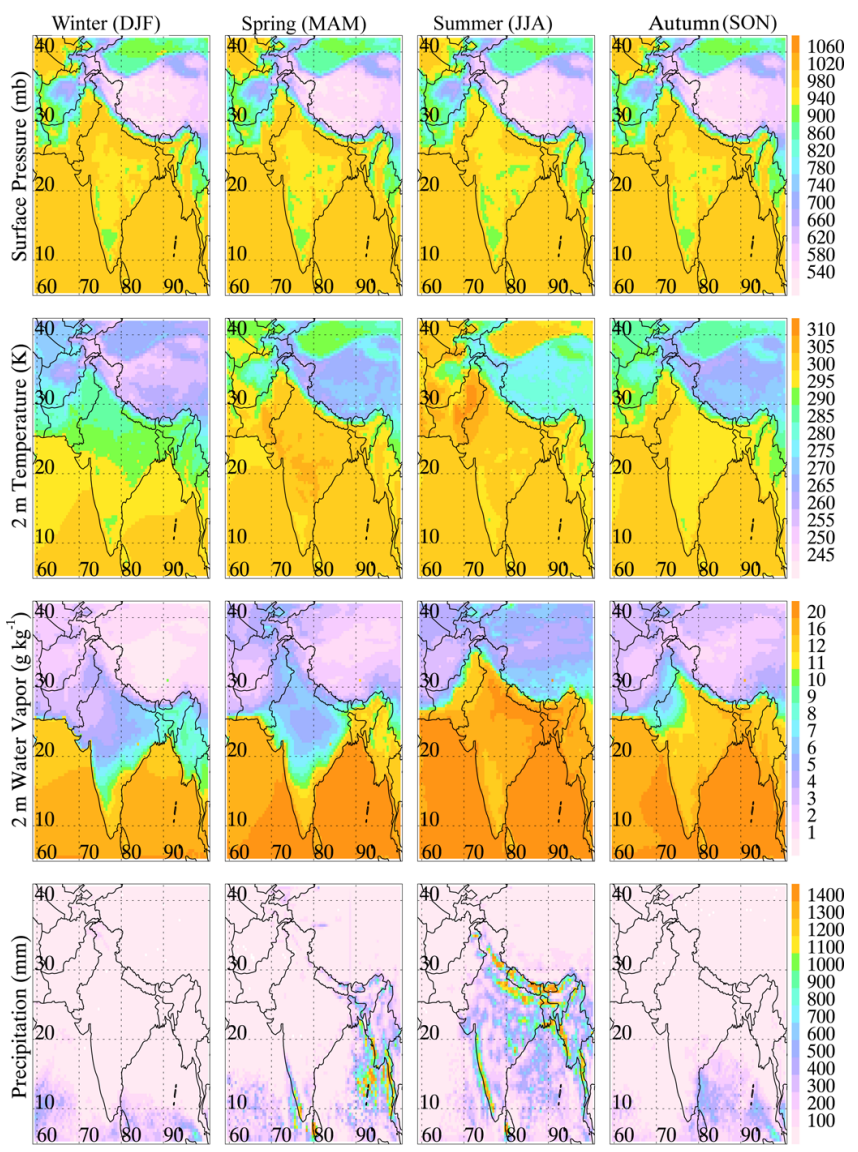

Fig. 2. Spatial distribution of the model simulated average near surface pressure, $2 \mathrm{~m}$ temperature, $2 \mathrm{~m}$ water vapor and total precipitation during winter, spring, summer and autumn seasons of the year 2008. For precipitation, the color scale is limited to $1400 \mathrm{~mm}$, but actual rainfall amounts can exceed this limit.

The seasonal total rainfall in spring also exceeds $1400 \mathrm{~mm}$ over the parts of Bay of Bengal and southern tip of India. Model simulated average $10 \mathrm{~m}$ wind patterns for January, April, July and November (representing the winter, spring, summer and autumn seasons, respectively) are shown in Fig. 3. Average surface winds are weaker over the land regions than over the oceanic regions during all the seasons because of the low surface roughness over the oceans compared to the land. During winter, surface temperatures over South Asian land-masses are lower than over the oceanic regions. This leads to the development of a high pressure area over land and a low pressure area over the ocean, causing a low level north-easterly air flow near the surface over most of the model domain. Over the Himalayan region, including the Tibetan Plateau, the wintertime wind patterns are generally south-westerly. During the transition from winter to spring, land regions warm up rapidly leading to the formation of heat lows over the subcontinent and cold highs over the oceanic regions. Thus, springtime near-surface winds are nearly zonal over the regions north of $20^{\circ} \mathrm{N}$ while winds are 

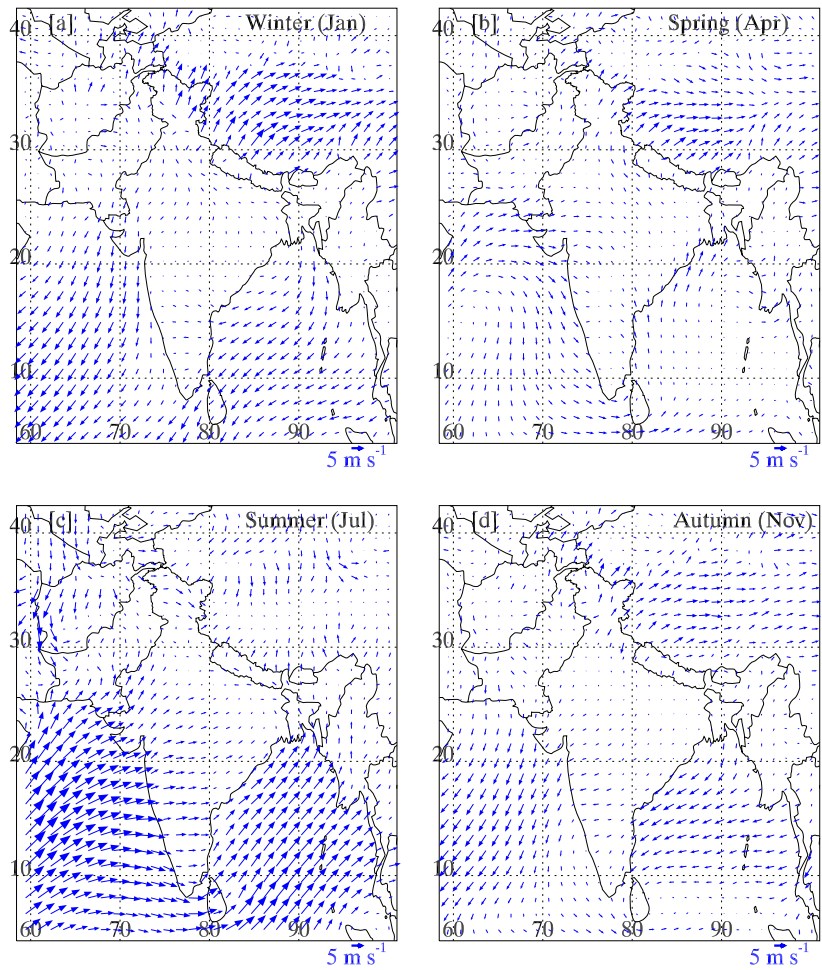

Fig. 3. Simulated average wind vectors over the model domain during (a) January, (b) April, (c) July and (d) November. The wind vectors are shown at every third grid point $(135 \mathrm{~km})$ for the clarity.

northerly over the Arabian Sea and southerly over the Bay of Bengal. The continuous heating of land mass during spring leads to the development of the South Asian monsoon during early summer and south-westerly near-surface winds prevail during summer. Surface temperature again decreases over land from summer to autumn and consequently the winds again change to a north-easterly direction.

Clearly, the summertime winds are stronger as compared to any other seasons. The southwesterly winds transport moist air masses from the oceans to inland regions during summer and thus lead to highest water vapor mixing ratios and precipitation over the domain in this season when the South Asian monsoon occurs. Such seasonal changes in temperature, water vapor, precipitation and the wind patterns are typical feature of the South Asian meteorology (e.g. Asnani, 2005), which appears to be very well replicated by the model. The errors in the simulated meteorological fields are quantified in the subsequent sections by comparison to satellite retrievals, reanalysis fields and radiosonde observations.

\subsection{AIRS temperature and water vapor}

The spatial distributions of AIRS retrieved and WRF-Chem simulated temperature and water vapor values at $700 \mathrm{hPa}$ during winter (DJF), spring (MAM), summer (JJA) and autumn (SON) of the year 2008 are depicted in Fig. 4. The
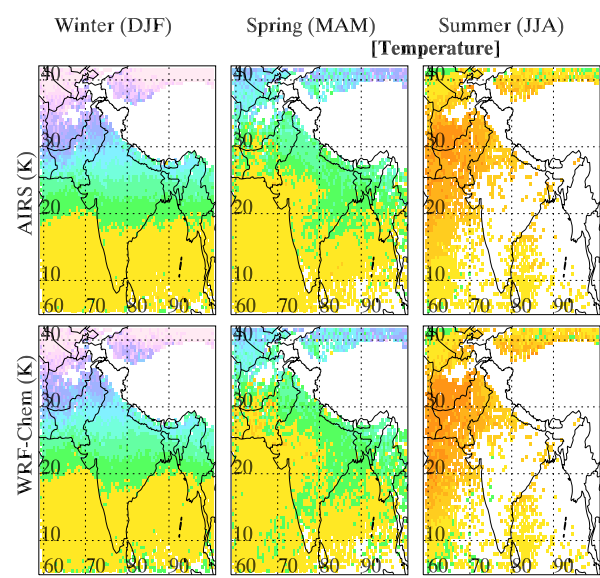

Autumn (SON)
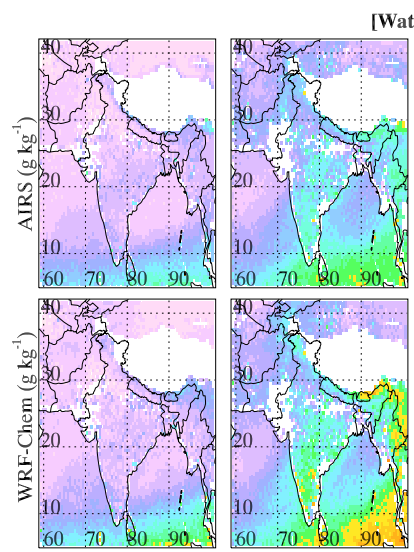

[Water Vapor]
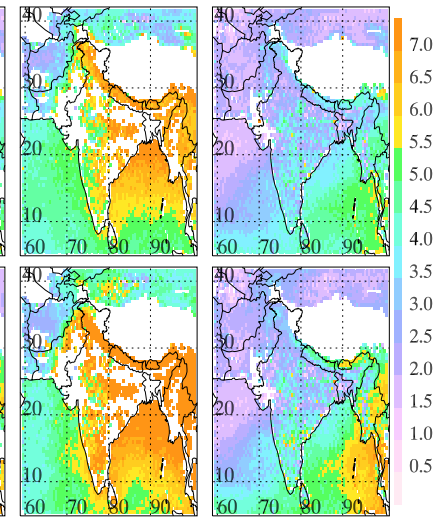

Fig. 4. Spatial distribution of co-located AIRS retrieved and simulated average temperature (first and second rows) and water vapor (third and fourth rows) at $700 \mathrm{hPa}$ during the winter (DJF), spring (MAM), summer (JJA) and autumn (SON) seasons of the year 2008. The white space indicates missing data.

model data have been co-located in both space and time with the quality controlled AIRS retrievals (Sect. 3.4). The model simulated spatial and temporal variations in temperature and water vapor distribution at $700 \mathrm{hPa}$ are similar to those seen near the surface (Fig. 2). Both the model and AIRS retrieval at $700 \mathrm{hPa}$ show that temperature and water vapor at this level generally increase from winter to summer and decrease during autumn. However, some differences between the AIRS retrieved and model simulated spatial distributions of water vapor are discernible in each season. The differences are most prominent during summer and can be noted over both the inland and oceanic regions. These differences are quantified using different statistical metrics and are discussed below.

The relationship between the AIRS and simulated temperature values at $700 \mathrm{hPa}$ for each season are shown as scatter plots and frequency analyses (Fig. 5). The scatter plots indicate a very strong correlation (both $r^{2}$ and index of agreement are greater than 0.85) between the AIRS and simulated values during all the seasons. Frequency analyses indicate 

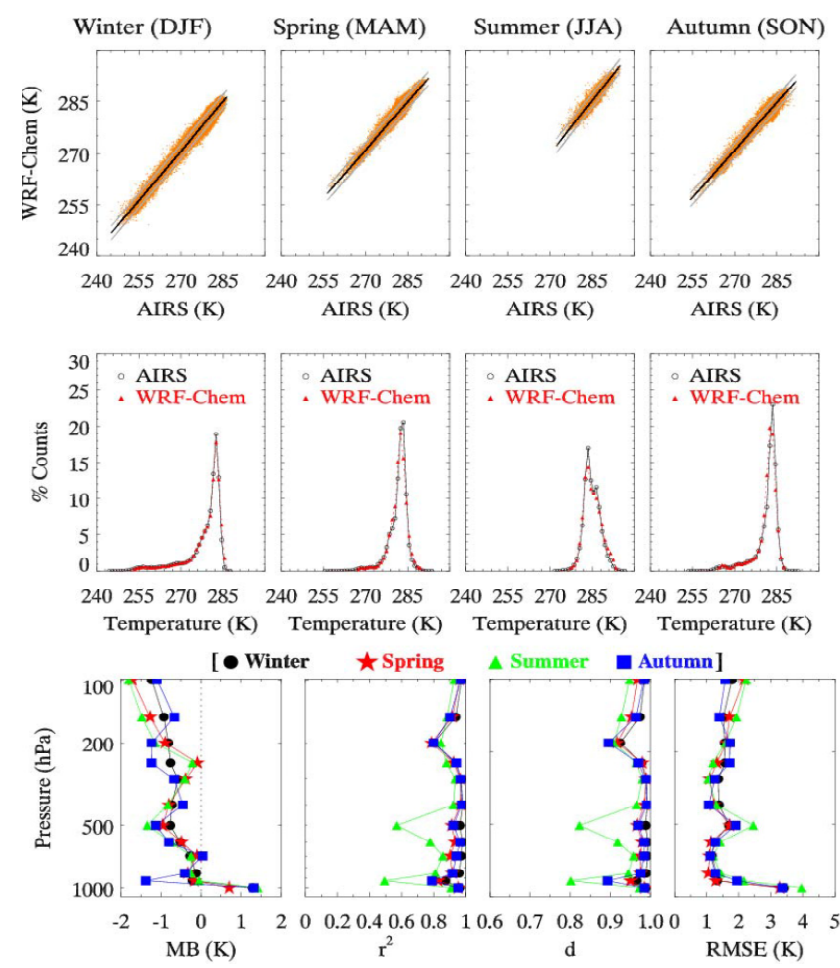

Fig. 5. The scatter plots (top panel) and the frequency analyses (middle panel) of AIRS and simulated temperature at $2 \mathrm{~K}$ interval for $700 \mathrm{hPa}$ during the four seasons of the year 2008. The black lines in the scatter plots represent the linear fit to the data while the grey lines are the $95 \%$ confidence interval estimates in the fitted values. The vertical profiles (bottom panel) of mean bias (MB), coefficient of determination $\left(r^{2}\right)$, index of agreement $(d)$ and root mean square error (RMSE) for each season are also shown.

similar distributions for the domain-wide AIRS and model temperature values among $2 \mathrm{~K}$ intervals and both distributions peak around $282-284 \mathrm{~K}$ temperature values during all seasons. Due to the distinct seasonal cycle, the temperature distributions are skewed towards lower values during winter and autumn as compared to spring and summer. The simulated temperature values at all other pressure levels between $1000 \mathrm{hPa} /$ surface pressure (whichever is lower) and $100 \mathrm{hPa}$ are also found to be in good agreement with the AIRS retrievals (Table 3). The model simulated average temperature values at individual pressure levels are within $\pm 1 \%$ of the AIRS retrieved value, respectively.

To quantify the differences in model and observations, the vertical profiles of $\mathrm{MB}, r^{2}$, index of agreement $(d)$ and RMSE in temperature for each season are shown in Fig. 5. The mean bias (MB) in the model simulated and AIRS retrieved temperature is estimated to be within $\pm 2 \mathrm{~K}$ at all pressure levels in all seasons. The model is generally biased cold at the surface and warm aloft with respect to the AIRS temperature. The cold bias at the surface might be due to the local closure model employed in the MYJ PBL scheme as this model allows the entrainment to develop only through local mixing, which partially leads to lower temperatures near the surface (Hu et al., 2010). Both $r^{2}$ and index of agreement show similar vertical profiles and higher values at all the pressure levels except at $925 \mathrm{hPa}$ and $500 \mathrm{hPa}$ during summer. This lower correlation in summer can partially be attributed to the fewer number of samples in this season. The estimated RMSE in temperature is largest at the surface $(3.3-3.9 \mathrm{~K})$ and is about $1-2 \mathrm{~K}$ at all other pressure levels. Larger differences at the surface can be caused by the uncertainty in the representation of the surface forcing physics, topography and land surface characteristics in the model due to its coarser resolution $(45 \mathrm{~km})$. Further, large errors in the AIRS surface temperature retrievals, due to heterogeneity of the land surface and the associated spectral emissivity variations (Divakarla et al., 2006) can also contribute to these differences. Like RMSE, both $\mathrm{RMSE}_{\mathrm{S}}$ and $\mathrm{RMSE}_{\mathrm{u}}$ are also estimated to be higher at the surface and lower aloft (not shown here). However, the RMSE in the model predicted temperature are estimated to be largely unsystematic except at $100 \mathrm{hPa}$.

The errors in simulated temperature can affect the air quality simulations by influencing biogenic emissions, gas phase chemistry, gas/particle partitioning of the semi volatile organic compounds, dry deposition of pollutants through the surface exchange scheme. In the absence of other errors, the cold model bias estimated here at the surface will tend to underestimate photochemical ozone production in the surface layer by lowering the emissions and slowing down the reaction rates while the warm bias aloft will tend to overestimate photochemical ozone production by enhancing reaction rates. The cold bias at the surface will also tend to underestimate the dry deposition of trace species by reducing the strength of mixing within the boundary layer. The adequacy of the model's meteorological performance is assessed by comparing estimated statistical metrics with a set of benchmarks proposed by Emery (2001) who suggested that errors in model simulated temperature will have little impact on air quality simulations if the index of agreement $(d)$ is greater than 0.8 , the mean bias (MB) is less than $\pm 0.5 \mathrm{~K}$ and the mean absolute error (MAE) is less than $2 \mathrm{~K}$. The index of agreement is estimated to be greater than 0.8 at all the pressure levels during all the seasons fulfilling the proposed criterion. MAE values (less than $1.5 \mathrm{~K}$ ) are also much smaller than the proposed criteria value $(2 \mathrm{~K})$ at all pressure levels except at the surface (2-2.5 K). Some part of the higher MAE values at the surface might be related to uncertainties involved in AIRS temperature retrievals as previously mentioned. The MB values (within $\pm 2 \mathrm{~K}$ ) in model simulated temperature are slightly higher than the proposed criteria value but they are not expected to induce large errors in the air quality simulations because temperature variations of $\pm 5 \mathrm{~K}$ are shown to induce errors of typically less than $\pm 10 \mathrm{ppbv}$ in simulating ozone concentrations (Vieno et al., 2010). 
Table 3. Domain-wide average and standard deviation of AIRS and WRF-Chem temperature values (K) at the surface and at different pressure levels between 925 and $100 \mathrm{hPa}$ during the winter, spring, summer and autumn seasons of the year 2008.

\begin{tabular}{|c|c|c|c|c|c|c|c|c|}
\hline \multirow{2}{*}{$\begin{array}{l}\text { Pressure } \\
(\mathrm{hPa})\end{array}$} & \multicolumn{2}{|c|}{ Winter } & \multicolumn{2}{|c|}{ Spring } & \multicolumn{2}{|c|}{ Summer } & \multicolumn{2}{|c|}{ Autumn } \\
\hline & AIRS* & $\mathrm{WRF}^{*}$ & AIRS* & $\mathrm{WRF}^{*}$ & AIRS* & $\mathrm{WRF}^{*}$ & AIRS* & $\mathrm{WRF}^{*}$ \\
\hline Surface & $285.1 \pm 15.4$ & $283.8 \pm 16$ & $293.3 \pm 13$ & $292.6 \pm 14$ & $293.1 \pm 12.2$ & $291.7 \pm 12.1$ & $291.3 \pm 13.2$ & $290.0 \pm 14$ \\
\hline 925 & $292.7 \pm 3.6$ & $292.9 \pm 3.7$ & $296.9 \pm 3.1$ & $297.1 \pm 2.8$ & $295.8 \pm 3.0$ & $295.8 \pm 2.1$ & $294.6 \pm 2.9$ & $295.9 \pm 2.9$ \\
\hline 850 & $287.2 \pm 6.2$ & $287.4 \pm 6.3$ & $292.3 \pm 3.4$ & $292.7 \pm 3.5$ & $293.1 \pm 3.2$ & $293.3 \pm 3.0$ & $290.3 \pm 4.0$ & $290.7 \pm 4.2$ \\
\hline 700 & $278.3 \pm 6.8$ & $278.6 \pm 6.6$ & $281.6 \pm 3.5$ & $281.7 \pm 3.4$ & $284.9 \pm 2.9$ & $285.1 \pm 3.1$ & $281.3 \pm 4.6$ & $281.2 \pm 4.3$ \\
\hline 600 & $270.9 \pm 7.6$ & $271.4 \pm 7.4$ & $273.2 \pm 4.0$ & $273.7 \pm 3.9$ & $276.1 \pm 2.5$ & $276.8 \pm 2.5$ & $273.2 \pm 5.1$ & $273.9 \pm 4.9$ \\
\hline 500 & $261.1 \pm 7.9$ & $261.9 \pm 7.7$ & $263.4 \pm 4.8$ & $264.4 \pm 4.6$ & $266.5 \pm 3.0$ & $267.8 \pm 2.9$ & $263.4 \pm 5.5$ & $264.5 \pm 5.4$ \\
\hline 400 & $249.7 \pm 7.5$ & $250.4 \pm 8.0$ & $251.7 \pm 4.9$ & $252.5 \pm 5.2$ & $256.3 \pm 3.4$ & $257.1 \pm 3.6$ & $252.1 \pm 5.5$ & $252.6 \pm 5.8$ \\
\hline 300 & $235.6 \pm 6.8$ & $236.2 \pm 7.2$ & $237.3 \pm 5.1$ & $237.8 \pm 5.4$ & $243.5 \pm 3.6$ & $243.9 \pm 3.8$ & $237.2 \pm 5.8$ & $237.9 \pm 5.8$ \\
\hline 250 & $227.5 \pm 5.2$ & $228.3 \pm 5.3$ & $229.1 \pm 4.5$ & $229.3 \pm 4.8$ & $235.4 \pm 3.4$ & $235.6 \pm 3.1$ & $228.2 \pm 5.0$ & $229.4 \pm 4.9$ \\
\hline 200 & $219.0 \pm 2.3$ & $219.8 \pm 2.7$ & $219.2 \pm 2.8$ & $220.1 \pm 2.9$ & $224.0 \pm 2.8$ & $225.1 \pm 2.4$ & $218.9 \pm 2.6$ & $220.2 \pm 2.7$ \\
\hline 150 & $209.0 \pm 4.8$ & $209.9 \pm 4.6$ & $208.2 \pm 3.9$ & $209.4 \pm 3.9$ & $210.9 \pm 3.6$ & $212.4 \pm 3.4$ & $209.1 \pm 3.9$ & $209.7 \pm 3.5$ \\
\hline 100 & $198.6 \pm 7.7$ & $199.8 \pm 7.2$ & $196.7 \pm 6.2$ & $198.3 \pm 5.7$ & $199.5 \pm 4.9$ & $201.2 \pm 4.8$ & $199.4 \pm 6.3$ & $200.5 \pm 6.1$ \\
\hline
\end{tabular}

* Mean \pm 1 Sigma.

Table 4. Same as Table 3 but for AIRS water vapor $\left(\mathrm{g} \mathrm{kg}^{-1}\right)$.

\begin{tabular}{|c|c|c|c|c|c|c|c|c|}
\hline \multirow{2}{*}{$\begin{array}{l}\text { Pressure } \\
(\mathrm{hPa})\end{array}$} & \multicolumn{2}{|c|}{ Winter } & \multicolumn{2}{|c|}{ Spring } & \multicolumn{2}{|c|}{ Summer } & \multicolumn{2}{|c|}{ Autumn } \\
\hline & AIRS* & $\mathrm{WRF}^{*}$ & AIRS* & WRF* $^{*}$ & AIRS* & WRF* $^{*}$ & AIRS* & WRF* \\
\hline 1000 & $12.8 \pm 3.2$ & $12.5 \pm 3.5$ & $14.4 \pm 3.0$ & $14.1 \pm 3.8$ & $16.1 \pm 1.7$ & $17.2 \pm 1.2$ & $14.8 \pm 2.7$ & $14.9 \pm 2.9$ \\
\hline 925 & $8.9 \pm 3.7$ & $7.9 \pm 3.6$ & $10.6 \pm 3.9$ & $9.1 \pm 4.0$ & $13.1 \pm 2.7$ & $13.6 \pm 2.3$ & $11.3 \pm 3.7$ & $10.5 \pm 3.6$ \\
\hline 850 & $4.0 \pm 2.6$ & $4.7 \pm 2.9$ & $5.8 \pm 2.9$ & $6.3 \pm 3.0$ & $8.0 \pm 2.3$ & $9.2 \pm 2.8$ & $6.1 \pm 3.0$ & $7.1 \pm 3.2$ \\
\hline 700 & $1.8 \pm 1.6$ & $2.1 \pm 1.9$ & $3.0 \pm 1.8$ & $3.4 \pm 2.1$ & $4.9 \pm 1.6$ & $5.3 \pm 2.1$ & $3.2 \pm 2.0$ & $3.6 \pm 2.5$ \\
\hline 600 & $1.0 \pm 1.0$ & $1.0 \pm 1.1$ & $1.6 \pm 1.3$ & $1.7 \pm 1.4$ & $3.5 \pm 1.5$ & $3.8 \pm 1.6$ & $2.0 \pm 1.5$ & $2.1 \pm 1.7$ \\
\hline 500 & $0.5 \pm 0.5$ & $0.5 \pm 0.5$ & $0.7 \pm 0.7$ & $0.8 \pm 0.7$ & $1.8 \pm 0.9$ & $2.1 \pm 1.1$ & $1.0 \pm 0.9$ & $1.1 \pm 0.9$ \\
\hline 400 & $0.2 \pm 0.2$ & $0.2 \pm 0.2$ & $0.3 \pm 0.3$ & $0.3 \pm 0.3$ & $0.7 \pm 0.5$ & $0.9 \pm 0.5$ & $0.4 \pm 0.4$ & $0.4 \pm 0.4$ \\
\hline 300 & $0.1 \pm 0.1$ & $0.1 \pm 0.1$ & $0.1 \pm 0.1$ & $0.1 \pm 0.1$ & $0.2 \pm 0.2$ & $0.3 \pm 0.2$ & $0.1 \pm 0.1$ & $0.2 \pm 0.2$ \\
\hline
\end{tabular}

* Mean \pm 1 Sigma.

The model simulated water vapor values at all pressure levels between $1000 \mathrm{hPa} /$ surface pressure (whichever is lower) and $300 \mathrm{hPa}$ are also found to be in good agreement with the AIRS retrievals (Table 4). The model simulated average water vapor values at individual pressure levels are within $\pm 17 \%$ of the AIRS retrieved average value respectively. The scatter plot between AIRS retrieved and model simulated water vapor values at $700 \mathrm{hPa}$ also show positive correlation (Fig. 6) but there is a larger scatter and weaker correlation compared to the comparison of temperature. Largest scatter is seen during summer. This is likely due to large spatial variability of water vapor associated with spatially varying influence of the South Asian monsoon in this region. Simulations of the Indian summer monsoon are difficult due to its anomalous characteristics in the tropical circulation. The frequency analyses of AIRS and the model water vapor values exhibit similar distributions. However, the model distribution gets slightly more contribution from higher water vapor mixing ratio as compared to the AIRS distribution in all the seasons. These higher model simulated water vapor values arise mainly due to an overestimation over much of the Bay of Bengal, along the western coasts of India and the Himalayan foothills in summer and over the southern Bay of Bengal, eastern Burma and northeast India during spring and autumn. These discrepancies could arise due to uncertainty in the representation of topography, insufficient mixing in the boundary layer, errors in moisture transport and simulation of surface moisture availability, soil temperature and an excessive water vapor flux from the ocean. However, it is difficult to diagnose the relative contributions of these processes due to the lack of in situ observations.

As before, Fig. 6 also shows the vertical profiles of MB, $r^{2}$, index of agreement and RMSE Here, these statistical metrics are calculated only up to $300 \mathrm{hPa}$ because AIRS has limited sensitivity to water vapor in the upper troposphere (Gettelman et al., 2004; Divakarla et al., 2006). Further, the MB and RMSE for water vapor are reported in percentage and are computed by weighting these metrics with the average 

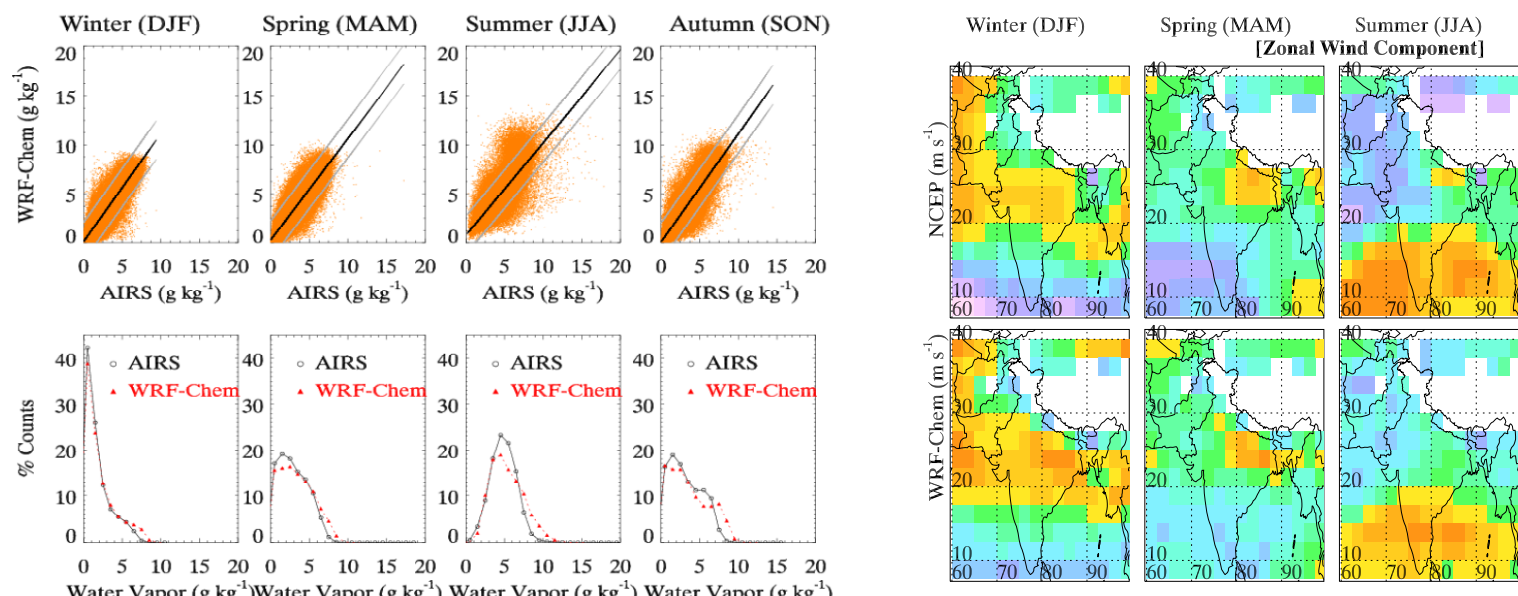

Autumn (SON)
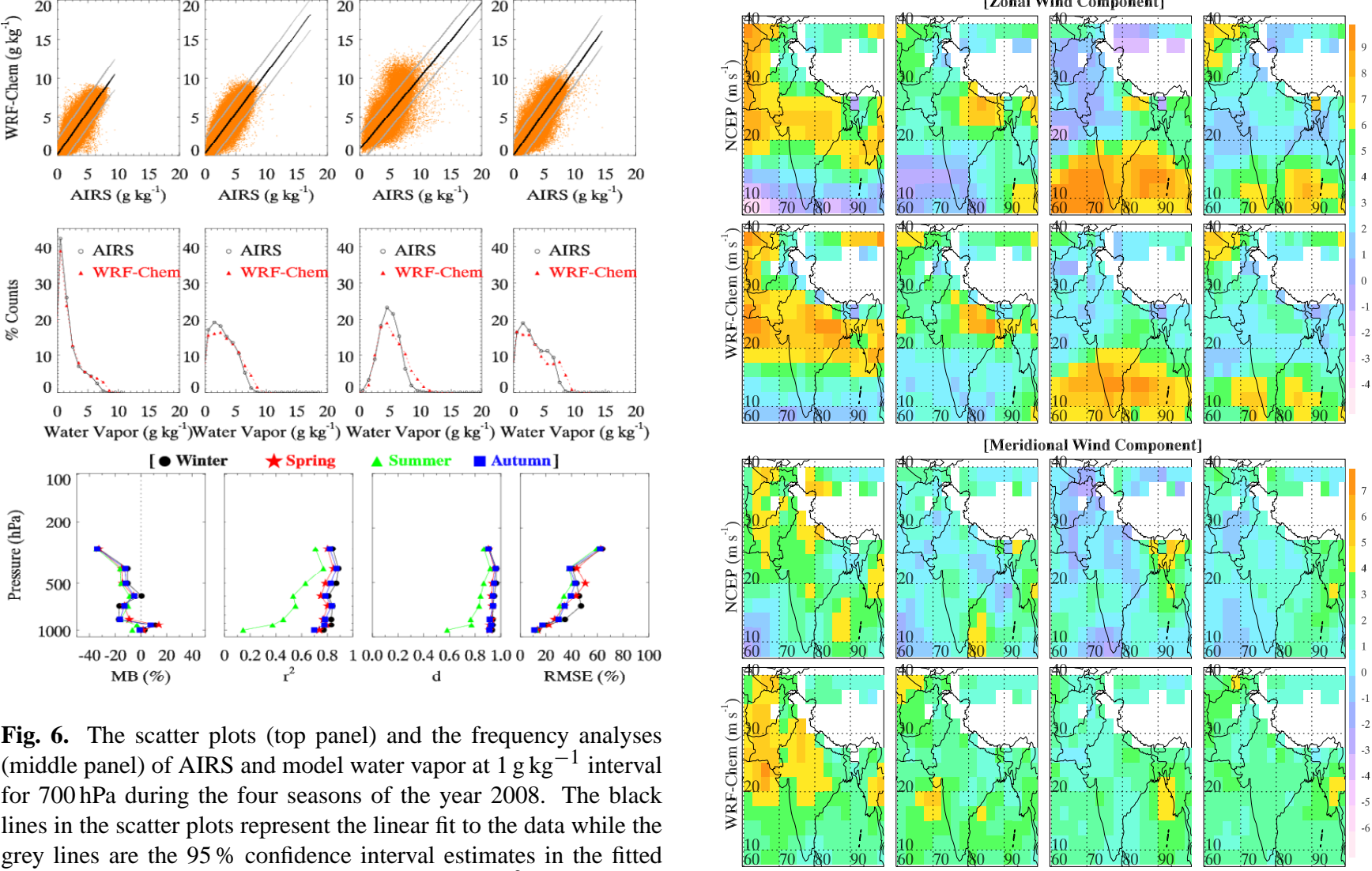

Fig. 6. The scatter plots (top panel) and the frequency analyses (middle panel) of AIRS and model water vapor at $1 \mathrm{~g} \mathrm{~kg}^{-1}$ interval for $700 \mathrm{hPa}$ during the four seasons of the year 2008. The black lines in the scatter plots represent the linear fit to the data while the grey lines are the $95 \%$ confidence interval estimates in the fitted values. The vertical profiles (bottom panel) of MB, $r^{2}, d$ and RMSE for each season are also show

AIRS water mixing ratio. The values of both $r^{2}$ and index of agreement in summer $\left(r^{2}: 0.14-0.77 ; d: 0.58-0.92\right)$ are significantly lower than those in any other season $\left(r^{2}\right.$ : $0.7-0.9 ; d: 0.91-0.97)$, which can partially be attributed to the relatively small number of data samples in this season. The model results are biased wet with respect to AIRS retrievals at all levels in summer and above $900 \mathrm{hPa}$ in other seasons. The model is biased dry below $900 \mathrm{hPa}$ in all other seasons except at $1000 \mathrm{hPa}$ in autumn. The mean bias remains less than $20 \%$ at all the pressure levels between 1000 and $400 \mathrm{hPa}$ and exceeds $30 \%$ at $300 \mathrm{hPa}$. The increase in RMSE at higher levels could be related to the errors in the simulated temperature and the reduction in the sensitivity of AIRS associated with the decrease in water vapor mixing ratios with altitude (Gettelman et al., 2004). The RMSE between AIRS and WRF water vapor profiles is less than $20 \%$ at $1000 \mathrm{hPa}$ and increase gradually to $60-65 \%$ at $300 \mathrm{hPa}$. Like temperature, RMSE in water vapor is also estimated to be largely unsystematic.

The errors in water vapor mixing ratios can also affect the concentrations of certain types of pollutants simulated by the model. For instance, a wet bias in the model can enhance the conversion of nitrogen species into aerosol nitrates at night.

Fig. 7. Spatial distribution of co-located NCEP and the model simulated average zonal (first and second rows) and meridional (third and fourth rows) wind components at $700 \mathrm{hPa}$ during the winter, spring, summer and autumn seasons of the year 2008. The white space indicates missing data in NCEP as well as in the model.

In fact, aerosol nitrate has been observed to increase significantly at night when relative humidity rises above $80 \%$ (Nenes et al., 1998). The wet bias of the model would also tend to overestimate the concentrations of hydroxyl radicals, which in turn would tend to underestimate the concentrations of several volatile organic compounds and would affect ozone. The set of benchmarks proposed for water vapor mixing ratio (Emery, 2001) suggest that index of agreement (d) should be greater than 0.6, mean bias (MB) should be less than $\pm 1 \mathrm{~g} \mathrm{~kg}^{-1}$ and mean absolute error (MAE) should be less than $2 \mathrm{~g} \mathrm{~kg}^{-1}$. The model evaluation shows that these metrics are well within the proposed benchmarks. Therefore, errors in simulation of water vapor are also expected to have little impact on air quality simulations in absence of other errors. The impact of biases in temperature and water vapor on the simulations of tropospheric ozone, $\mathrm{CO}$ and $\mathrm{NO}_{\mathrm{x}}$ will be assessed later in Sect. 4.6. 


\subsection{NCEP zonal and meridional winds}

The spatial distributions of the NCEP reanalysis and the model simulated zonal and meridional wind components $\left(2.5^{\circ}\right.$ resolution) at $700 \mathrm{hPa}$ during the four seasons of the year 2008 are shown in Fig. 7. The spatial distributions simulated by the model are fairly similar to the NCEP distributions. The model slightly overestimates both the zonal and meridional wind components during all the seasons except during summer over central/northern India, the Arabian Sea and the Bay of Bengal. In contrast, it slightly underestimates the zonal wind over the Arabian Sea and the Bay of Bengal during summer. The major factors limiting the accuracy of model simulated winds are likely linked to uncertainties in the simulation of the large scale pressure gradient, improper representation of topography and land surface characteristics due to coarser grid resolution $(45 \mathrm{~km}$ in this case) and errors in the initial and lateral boundary conditions (Bao et al., 2005). However, the initial conditions should play a minor role for long-term simulations. The model simulated domain-wide average values of both the wind components at all the pressure levels between 1000 and $100 \mathrm{hPa}$ are found to be in good agreement with the corresponding NCEP values (Tables 5 and 6). The average zonal and meridional wind component values simulated at different pressure levels by the model are within $\pm 15 \%$ of the corresponding NCEP values below $300 \mathrm{hPa}$.

Despite the above mentioned differences, the scatter plots indicate a reasonable positive correlation between NCEP fields and the model for both wind components (Figs. 8 and 9). The agreement is better in winter and autumn $\left(r^{2}=0.6-\right.$ $0.8)$ than in spring and summer $\left(r^{2}=0.4-0.7\right)$. The frequency analyses indicate very similar distributions for both NCEP and model wind components. The vertical profiles of $\mathrm{MB}, r^{2}, \mathrm{~d}$ and RMSE during all four seasons are also shown in Figs. 8 and 9, respectively. The mean bias in the zonal wind component is small $\left(0.6 \mathrm{~m} \mathrm{~s}^{-1}\right)$ below $300 \mathrm{hPa}$ while the model underestimates the zonal flow above $300 \mathrm{hPa}$ by $0.6-1.6 \mathrm{~m} \mathrm{~s}^{-1}$ during all the seasons. The mean bias in the meridional wind component is lower than the zonal wind component with the meridional wind component being overestimated by the model in the lower to middle troposphere $(850-500 \mathrm{hPa})$ by $0.1-0.7 \mathrm{~m} \mathrm{~s}^{-1}$ and underestimated in the upper troposphere $(300-100 \mathrm{hPa})$ by $0.1-0.5 \mathrm{~m} \mathrm{~s}^{-1}$. The $r^{2}$ and index of agreement for the zonal wind component $\left(r^{2}\right.$ : $0.61-0.98 ; d: 0.88-0.99)$ at all pressure levels are estimated to be better than for the meridional wind component $\left(r^{2}\right.$ : $0.38-0.94 ; d: 0.78-0.98$ ) in all seasons. The RMSE in both the zonal and meridional wind components exhibit an increasing tendency with altitude and are estimated to be 2.3$5.1 \mathrm{~m} \mathrm{~s}^{-1}$ and $2.2-3.9 \mathrm{~m} \mathrm{~s}^{-1}$ respectively. However, the relative error in zonal wind component decrease with altitude due to increase in wind speed at higher altitudes during all the seasons except during summer when relative error first increase up to $500 \mathrm{hPa}$ and then decrease up to $100 \mathrm{hPa}$. Like

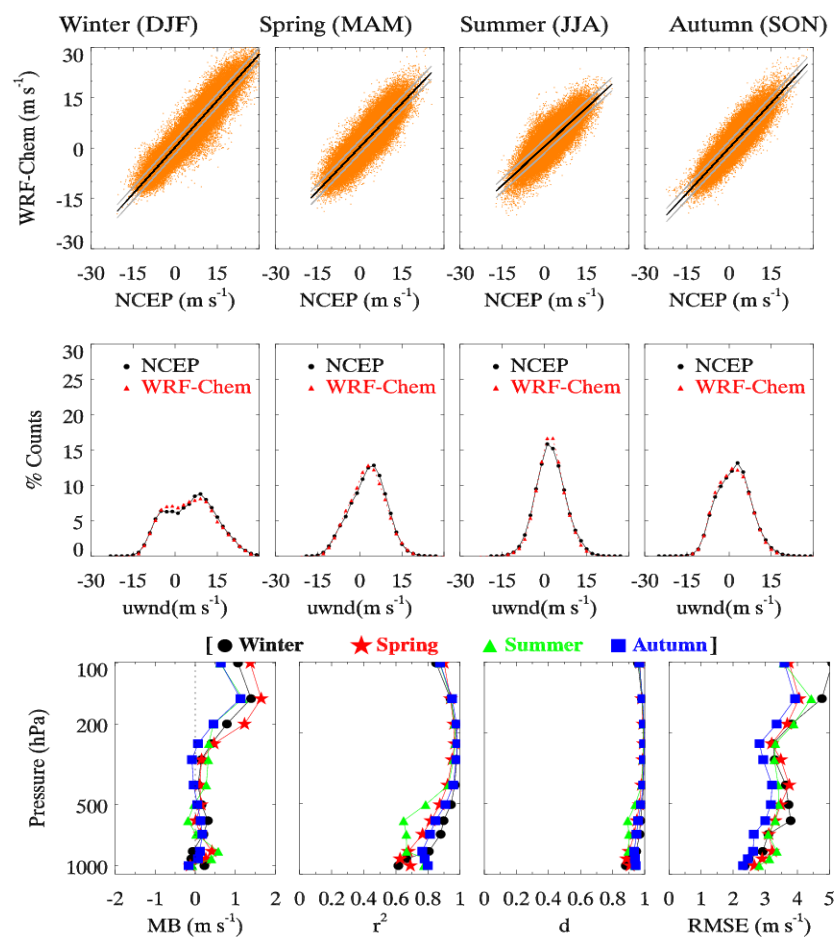

Fig. 8. The scatter plots (top panel) and the frequency analyses (middle panel) of NCEP and model zonal wind component at $2 \mathrm{~m} \mathrm{~s}^{-1}$ interval for $700 \mathrm{hPa}$ during the four seasons of the year 2008. The black lines in the scatter plots represent the linear fit to the data while the grey lines are the $95 \%$ confidence interval estimates in the fitted values. The vertical profiles (bottom panel) of $\mathrm{MB}, r^{2}, d$ and RMSE for each season are also shown.

temperature and water vapor, the RMSE in wind components are estimated to be mainly unsystematic.

The benchmarks proposed for wind speed (Emery, 2001) suggest that index of agreement $(d)$ should be greater than 0.6 , mean bias (MB) should be less than $\pm 0.5 \mathrm{~m} \mathrm{~s}^{-1}$ and root mean square error (RMSE) should be less than $2 \mathrm{~m} \mathrm{~s}^{-1}$. The index of agreement for both components is well above the proposed benchmark. The mean bias in both the wind components below $300 \mathrm{hPa}$ is well within the proposed benchmark limits but RMSE values are slightly higher than the benchmark values. The estimated mean bias $\left(<0.6 \mathrm{~m} \mathrm{~s}^{-1}\right)$ in both wind components below $300 \mathrm{hPa}$ can cause the transport of pollutants to be off by about $52 \mathrm{~km}$ in $24 \mathrm{~h}$ which is greater than the grid spacing of the model used here. de Meij et al. (2009) found that ozone levels over the mountain areas near Po Valley in their chemistry transport model simulations driven by WRF meteorology are higher by $6-9$ ppbv than those driven by MM5 meteorology and attributed these discrepancy to the difference of about $1 \mathrm{~m} \mathrm{~s}^{-1}$ between monthly mean wind speed of WRF and MM5. The overestimation of ozone concentrations due to larger wind speeds has also been reported over the subalpine mountain ranges (Minguzzi et al., 2005). The impact of biases in zonal and meridional 
Table 5. Domain-wide average and standard deviation of zonal component of NCEP and WRF winds at different pressure levels between $1000 \mathrm{hPa}$ and $100 \mathrm{hPa}$ during winter, spring, summer and autumn of 2008.

\begin{tabular}{|c|c|c|c|c|c|c|c|c|}
\hline \multirow{2}{*}{$\begin{array}{l}\text { Pressure } \\
(\mathrm{hPa})\end{array}$} & \multicolumn{2}{|c|}{ Winter } & \multicolumn{2}{|c|}{ Spring } & \multicolumn{2}{|c|}{ Summer } & \multicolumn{2}{|c|}{ Autumn } \\
\hline & NCEP* & $\mathrm{WRF}^{*}$ & NCEP* & $\mathrm{WRF}^{*}$ & NCEP* & $\mathrm{WRF}^{*}$ & NCEP* & $\mathrm{WRF}^{*}$ \\
\hline 1000 & $3.0 \pm 2.0$ & $3.4 \pm 2.2$ & $3.1 \pm 2.2$ & $3.5 \pm 2.4$ & $6.2 \pm 3.2$ & $6.8 \pm 3.0$ & $3.2 \pm 2.4$ & $3.7 \pm 2.7$ \\
\hline 925 & $3.2 \pm 2.4$ & $3.5 \pm 2.5$ & $3.7 \pm 3.0$ & $4.0 \pm 3.1$ & $7.1 \pm 4.8$ & $7.4 \pm 4.8$ & $3.7 \pm 3.1$ & $4.0 \pm 3.2$ \\
\hline 850 & $3.3 \pm 2.5$ & $3.4 \pm 2.6$ & $3.6 \pm 2.9$ & $3.7 \pm 2.9$ & $7.3 \pm 5.4$ & $7.2 \pm 5.3$ & $3.8 \pm 3.3$ & $3.9 \pm 3.3$ \\
\hline 700 & $5.5 \pm 3.8$ & $5.6 \pm 4.0$ & $4.4 \pm 3.1$ & $4.5 \pm 3.3$ & $5.2 \pm 4.3$ & $4.8 \pm 3.8$ & $4.2 \pm 3.3$ & $4.1 \pm 3.2$ \\
\hline 600 & $8.6 \pm 5.9$ & $8.3 \pm 6.0$ & $5.6 \pm 3.9$ & $5.5 \pm 4.0$ & $4.4 \pm 3.5$ & $4.2 \pm 3.3$ & $5.0 \pm 3.6$ & $4.9 \pm 3.6$ \\
\hline 500 & $12.7 \pm 8.5$ & $12.0 \pm 8.4$ & $7.6 \pm 5.3$ & $7.2 \pm 5.2$ & $4.4 \pm 3.5$ & $4.2 \pm 3.3$ & $6.6 \pm 5.0$ & $6.5 \pm 5.0$ \\
\hline 400 & $17.8 \pm 12.3$ & $17.4 \pm 11.9$ & $10.3 \pm 7.7$ & $9.9 \pm 7.4$ & $5.7 \pm 4.6$ & $5.6 \pm 4.5$ & $9.4 \pm 7.5$ & $9.3 \pm 7.5$ \\
\hline 300 & $24.1 \pm 17.0$ & $23.8 \pm 16.7$ & $14.6 \pm 11.2$ & $14.2 \pm 10.9$ & $10.1 \pm 7.3$ & $10.1 \pm 7.2$ & $14.3 \pm 11.1$ & $14.2 \pm 11.1$ \\
\hline 250 & $27.2 \pm 19.2$ & $26.9 \pm 19.0$ & $17.3 \pm 12.9$ & $17.0 \pm 12.8$ & $13.3 \pm 8.7$ & $13.3 \pm 8.6$ & $17.4 \pm 13.0$ & $17.3 \pm 13.0$ \\
\hline 200 & $29.0 \pm 20.3$ & $28.8 \pm 19.8$ & $19.7 \pm 14.0$ & $19.3 \pm 13.7$ & $16.5 \pm 9.7$ & $16.5 \pm 9.5$ & $20.1 \pm 14.3$ & $20.0 \pm 14.1$ \\
\hline 150 & $27.9 \pm 18.5$ & $27.7 \pm 17.7$ & $19.3 \pm 13.0$ & $18.7 \pm 12.3$ & $19.2 \pm 10.3$ & $19.2 \pm 10.4$ & $20.2 \pm 13.5$ & $20.2 \pm 13.1$ \\
\hline 100 & $20.7 \pm 13.5$ & $21.0 \pm 13.0$ & $13.9 \pm 9.0$ & $13.9 \pm 8.6$ & $19.0 \pm 10.9$ & $19.6 \pm 10.4$ & $14.2 \pm 9.8$ & $14.7 \pm 9.3$ \\
\hline
\end{tabular}

* Mean \pm 1 Sigma.

Table 6. Same as the Table 5 but for the meridional wind component.

\begin{tabular}{|c|c|c|c|c|c|c|c|c|}
\hline \multirow{2}{*}{$\begin{array}{l}\text { Pressure } \\
(\mathrm{hPa})\end{array}$} & \multicolumn{2}{|c|}{ Winter } & \multicolumn{2}{|c|}{ Spring } & \multicolumn{2}{|c|}{ Summer } & \multicolumn{2}{|c|}{ Autumn } \\
\hline & NCEP* & $\mathrm{WRF}^{*}$ & NCEP* & $\mathrm{WRF}^{*}$ & NCEP* & $\mathrm{WRF}^{*}$ & NCEP* & $\mathrm{WRF}^{*}$ \\
\hline 1000 & $3.4 \pm 2.3$ & $3.7 \pm 2.5$ & $2.8 \pm 2.1$ & $3.0 \pm 2.2$ & $4.5 \pm 2.9$ & $4.7 \pm 2.7$ & $2.7 \pm 2.0$ & $3.0 \pm 2.1$ \\
\hline 925 & $2.9 \pm 2.2$ & $3.1 \pm 2.4$ & $2.6 \pm 2.0$ & $3.0 \pm 2.4$ & $4.1 \pm 3.1$ & $4.5 \pm 3.3$ & $2.6 \pm 2.1$ & $2.8 \pm 2.2$ \\
\hline 850 & $2.8 \pm 2.2$ & $2.7 \pm 2.2$ & $2.4 \pm 1.9$ & $2.5 \pm 2.1$ & $3.4 \pm 2.6$ & $3.4 \pm 2.6$ & $2.6 \pm 2.0$ & $2.5 \pm 2.2$ \\
\hline 700 & $3.7 \pm 3.0$ & $3.4 \pm 2.9$ & $3.1 \pm 2.4$ & $3.2 \pm 2.7$ & $3.0 \pm 2.3$ & $2.9 \pm 2.4$ & $2.9 \pm 2.3$ & $2.8 \pm 2.4$ \\
\hline 600 & $4.1 \pm 3.4$ & $4.3 \pm 3.4$ & $3.3 \pm 2.6$ & $3.3 \pm 2.8$ & $3.0 \pm 2.5$ & $2.9 \pm 2.5$ & $3.1 \pm 2.5$ & $2.9 \pm 2.5$ \\
\hline 500 & $5.1 \pm 4.3$ & $5.5 \pm 4.4$ & $3.7 \pm 3.0$ & $3.6 \pm 3.0$ & $3.0 \pm 2.6$ & $2.9 \pm 2.5$ & $3.4 \pm 2.9$ & $3.3 \pm 3.0$ \\
\hline 400 & $6.4 \pm 5.5$ & $7.3 \pm 5.6$ & $4.4 \pm 3.8$ & $4.4 \pm 3.8$ & $3.0 \pm 2.5$ & $2.9 \pm 2.5$ & $4.0 \pm 3.7$ & $4.0 \pm 3.8$ \\
\hline 300 & $8.1 \pm 7.3$ & $8.2 \pm 7.4$ & $5.8 \pm 5.1$ & $5.8 \pm 5.2$ & $3.4 \pm 3.2$ & $3.6 \pm 3.4$ & $5.0 \pm 5.0$ & $5.1 \pm 5.2$ \\
\hline 250 & $9.1 \pm 8.2$ & $8.4 \pm 8.3$ & $6.6 \pm 5.8$ & $6.6 \pm 5.8$ & $3.9 \pm 3.8$ & $4.2 \pm 4.0$ & $5.7 \pm 5.7$ & $5.7 \pm 5.7$ \\
\hline 200 & $9.7 \pm 8.4$ & $6.9 \pm 8.4$ & $6.9 \pm 5.8$ & $7.0 \pm 5.8$ & $4.8 \pm 4.4$ & $5.0 \pm 4.4$ & $6.3 \pm 5.9$ & $6.4 \pm 5.9$ \\
\hline 150 & $8.7 \pm 6.9$ & $4.6 \pm 6.8$ & $6.2 \pm 4.8$ & $6.3 \pm 4.8$ & $5.5 \pm 4.5$ & $5.8 \pm 4.5$ & $6.1 \pm 5.2$ & $6.2 \pm 5.2$ \\
\hline 100 & $5.9 \pm 4.6$ & $3.2 \pm 4.7$ & $4.4 \pm 3.4$ & $4.0 \pm 3.1$ & $5.0 \pm 3.8$ & $4.7 \pm 3.5$ & $4.2 \pm 3.4$ & $3.8 \pm 3.2$ \\
\hline
\end{tabular}

$*$ Mean \pm sigma.

wind components along with those of temperature and water vapor on the simulations of tropospheric ozone, $\mathrm{CO}$ and $\mathrm{NO}_{\mathrm{x}}$ will be assessed later in Sect. 4.6.

\subsection{TRMM precipitation}

The spatial distributions of precipitation observed by TRMM and simulated by the model along with the absolute difference (WRF-TRMM) are depicted in Fig. 10. The seasonal cycle of the precipitation as seen by TRMM is successfully captured by the model. Both TRMM and the model show highest precipitation during summer and lowest during winter with some differences in the absolute magnitude and spatial distributions. In general, the difference between the model and TRMM rainfall values is within $\pm 10 \mathrm{~mm} \mathrm{day}^{-1}$ over much of the domain and during all the seasons except during summer, when the model overestimates the precipitation by more than $20 \mathrm{~mm} \mathrm{day}^{-1}$ along the Himalayas, the coastline in eastern regions like Bangladesh, Burma and west coast of India.

Accurate simulations of summertime rainfall over the Indian region have been a challenging task due to its anomalous characteristics in tropical circulation. Different studies based on regional meteorological models (MM5 or WRF) show that summer monsoonal rainfall is not very well simulated by these regional models (e.g. Ratnam and Kumar, 2005; Rakesh et al., 2009). Analysis of modeled precipitation showed that summer rainfall over India is dominated by convective precipitation and hence overestimation in the model could be due to use of the Kain-Fritsch scheme in 

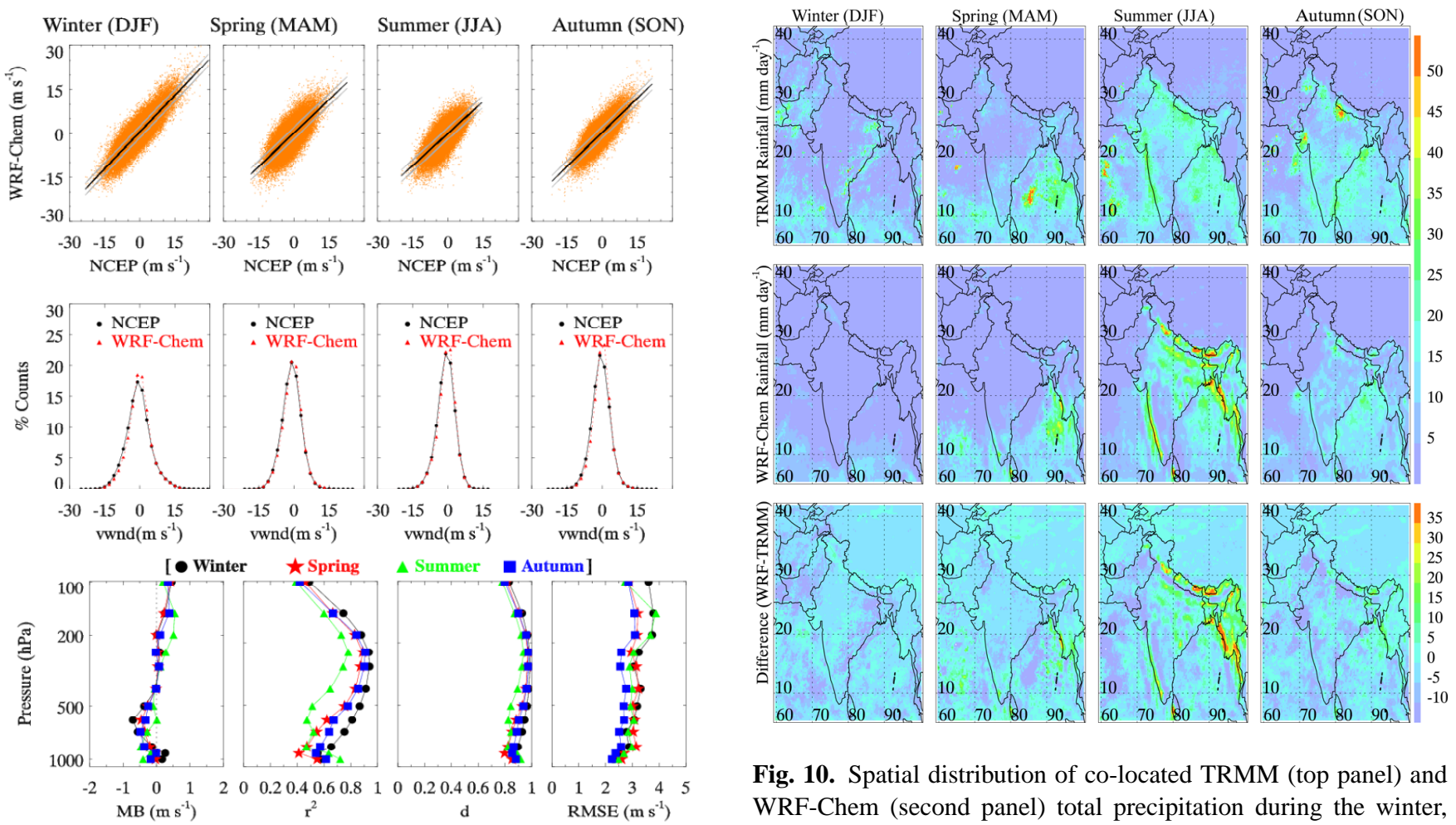

Fig. 10. Spatial distribution of co-located TRMM (top panel) and WRF-Chem (second panel) total precipitation during the winter, spring, summer and autumn seasons of the year 2008. Difference (WRF-TRMM) in the total precipitation values are shown in the bottom panel.

(middle panel) of NCEP and model meridional wind component at $2 \mathrm{~m} \mathrm{~s}^{-1}$ interval for $700 \mathrm{hPa}$ during the four seasons of the year 2008. The black lines in the scatter plots represent the linear fit to the data while the grey lines are the $95 \%$ confidence interval estimates in the fitted values. The vertical profiles (bottom panel) of MB, $r^{2}, d$ and RMSE for each season are also shown.

the model. Rakesh et al. (2009) used the same convective scheme (Kain-Fritsch) and also found that the WRF model overestimates the summertime rainfall over this region. The discrepancies between TRMM and the model can be attributed to the coarse model resolution $(45 \mathrm{~km})$, errors in the lateral boundary conditions, uncertainties associated with the parameterization of physical processes in the model and errors in the grid resolvable meteorological variables related to the precipitation (e.g. temperature, water vapor and heat fluxes). Sensitivity simulations indicate that estimated biases in modeled temperature and water vapor can lead to errors of $\pm(1-8) \mathrm{mm} \mathrm{day}^{-1}$ in modeled precipitation. Further, the lower accuracy of TRMM retrievals in regions of sharp rainfall gradients, warm clouds and rapidly varying orography (Nair et al., 2009) may also contribute to these differences.

In order to quantify the domain-wide differences between TRMM and WRF precipitation, the hit rate statistics is calculated during each season at 11 rainfall threshold values $(1,5$, 10, 15, 20, 25, 30, 35, 40, 45, 50; all values in $\mathrm{mm} \mathrm{day}^{-1}$ ) and is shown in Table 7. The evaluation at 11 threshold values provides the information about the model skill in simulating

a range of precipitation events. The values of probability of detection (POD) and false alarm rate (FAR), which range from $0.1-0.76$ and $0-0.34$, respectively, are highest in summer and lowest in winter. However, the Hansen-Kuipers Score (HKS) and odds ratios (ORT) values, which range from $0.1-0.52$ and 6.25-91.7, respectively, are highest in winter and lowest in summer. The frequency bias index (FBI) values, which range from $0.44-1.08$, indicate that the model generally overestimates the domain-wide precipitation observed by the TRMM except for the precipitation events exceeding the threshold of $40 \mathrm{~mm} \mathrm{day}^{-1}$ in winter. Both POD and FAR show a decreasing tendency with increase in rainfall threshold but the ORT values indicate that the probability of detecting a rainfall event by the model above any rainfall threshold is greater than the false simulation of rainfall events. However, the simultaneous increase in FBI values and decrease in HKS score with increasing rainfall threshold indicate deterioration in the model skill for heavier precipitation events.

\subsection{Radiosonde observations - temperature and dew point temperature}

Model simulated temperature and dew point temperature are compared with the 00:00 and 12:00 UTC radiosonde observations (RAOB) at 34 stations (Table 1; Fig. 1) within the 
Table 7. Hit rate statistics (probability of detection (POD), false alarm rate (FAR), frequency bias (FBI), Hansen-Kuipers Score (HKS) and odd ratio (ORT)) for WRF-Chem and TRMM daily precipitation data during winter, spring, summer and autumn at different threshold values.

\begin{tabular}{|c|c|c|c|c|c|c|c|c|c|c|c|c|}
\hline & \multirow{2}{*}{ Season } & \multicolumn{11}{|c|}{ Threshold Precipitation $\left(\mathrm{mm}\right.$ day $\left.^{-1}\right)$} \\
\hline & & 1 & 5 & 10 & 15 & 20 & 25 & 30 & 35 & 40 & 45 & 50 \\
\hline \multirow{4}{*}{ POD } & Winter & 0.59 & 0.55 & 0.51 & 0.46 & 0.40 & 0.35 & 0.30 & 0.25 & 0.20 & 0.14 & 0.10 \\
\hline & Spring & 0.62 & 0.55 & 0.49 & 0.44 & 0.40 & 0.36 & 0.32 & 0.29 & 0.25 & 0.22 & 0.18 \\
\hline & Summer & 0.76 & 0.67 & 0.60 & 0.54 & 0.49 & 0.44 & 0.39 & 0.34 & 0.30 & 0.26 & 0.22 \\
\hline & Autumn & 0.67 & 0.61 & 0.56 & 0.51 & 0.45 & 0.40 & 0.35 & 0.30 & 0.26 & 0.22 & 0.18 \\
\hline \multirow{4}{*}{ FAR } & Winter & 0.09 & 0.04 & 0.03 & 0.02 & 0.01 & 0.01 & 0.01 & 0.01 & 0.00 & 0.00 & 0.00 \\
\hline & Spring & 0.15 & 0.09 & 0.06 & 0.05 & 0.04 & 0.03 & 0.02 & 0.02 & 0.01 & 0.01 & 0.01 \\
\hline & Summer & 0.34 & 0.25 & 0.19 & 0.16 & 0.13 & 0.10 & 0.08 & 0.06 & 0.05 & 0.04 & 0.03 \\
\hline & Autumn & 0.14 & 0.10 & 0.08 & 0.06 & 0.05 & 0.04 & 0.03 & 0.02 & 0.01 & 0.01 & 0.01 \\
\hline \multirow{4}{*}{ FBI } & Winter & 0.60 & 0.64 & 0.62 & 0.62 & 0.65 & 0.70 & 0.76 & 0.86 & 1.02 & 1.30 & 1.80 \\
\hline & Spring & 0.72 & 0.65 & 0.60 & 0.57 & 0.56 & 0.55 & 0.56 & 0.58 & 0.62 & 0.67 & 0.73 \\
\hline & Summer & 0.69 & 0.60 & 0.52 & 0.48 & 0.46 & 0.44 & 0.45 & 0.46 & 0.47 & 0.50 & 0.54 \\
\hline & Autumn & 0.78 & 0.70 & 0.65 & 0.63 & 0.63 & 0.65 & 0.68 & 0.72 & 0.79 & 0.88 & 1.00 \\
\hline \multirow{4}{*}{ HKS } & Winter & 0.50 & 0.51 & 0.48 & 0.44 & 0.39 & 0.34 & 0.29 & 0.25 & 0.20 & 0.14 & 0.10 \\
\hline & Spring & 0.48 & 0.46 & 0.43 & 0.39 & 0.36 & 0.33 & 0.30 & 0.27 & 0.24 & 0.21 & 0.18 \\
\hline & Summer & 0.42 & 0.43 & 0.41 & 0.39 & 0.37 & 0.34 & 0.31 & 0.28 & 0.25 & 0.22 & 0.19 \\
\hline & Autumn & 0.52 & 0.51 & 0.48 & 0.45 & 0.41 & 0.36 & 0.32 & 0.28 & 0.24 & 0.21 & 0.17 \\
\hline \multirow{4}{*}{ ORT } & Winter & 14.2 & 27.3 & 37.3 & 44.3 & 49.6 & 55.6 & 62.0 & 70.2 & 79.4 & 84.2 & 91.7 \\
\hline & Spring & 9.6 & 12.5 & 14.6 & 16.2 & 18.1 & 20.4 & 22.7 & 25.3 & 28.2 & 31.4 & 34.9 \\
\hline & Summer & 6.3 & 6.3 & 6.2 & 6.4 & 6.7 & 7.1 & 7.4 & 7.9 & 8.6 & 9.4 & 10.2 \\
\hline & Autumn & 12.0 & 14.1 & 15.2 & 16.2 & 17.0 & 18.3 & 19.8 & 21.6 & 23.6 & 26.6 & 29.5 \\
\hline
\end{tabular}

simulation domain. The seasonal variations of the RAOB and the model simulated temperature and dew point temperature at the surface, $700 \mathrm{hPa}, 500 \mathrm{hPa}$ and $300 \mathrm{hPa}$ for Delhi (DEL), Bangalore (BAN), Thiruvanantpuram (THI) and Port-Blair (POR) are shown in Fig. 11. DEL, BAN, THI and POR are selected to represent the low altitude, moderately high altitude, coastal and island sites respectively. In general, the seasonal variations of both the temperature and dew point temperature simulated by the model at all the pressure levels are in reasonably good agreement with the observations. Some differences between model and observed values of the dew point temperature are seen at higher altitudes. The discrepancies for dew point temperature are consistent with the model-AIRS water vapor comparison for which an increase in RMSE is seen with altitude (Fig. 6). Port Blair, an island site, shows some differences at surface levels as the model is not able to separate out island with the oceanic region; this will be discussed later in this section. Like AIRS retrievals, RAOB observations also show differences in the seasonal cycle amplitude for the sites located north and south of the $20^{\circ} \mathrm{N}$ latitude belt. The seasonal amplitudes at DEL are clearly larger than those at BAN, THI and POR and this difference is also very well replicated by the model.

Figure 12 shows the vertical profiles of the statistical metrics for the temperature and dew point temperature at all the sites belonging to the low altitude, moderately high altitude, coastal and island sites respectively. The correlation $\left(r^{2}\right)$ is better for temperature for the case of low altitude and moderately high altitude sites below $300 \mathrm{hPa}$. The poorer correlation at the coastal and island sites appears to be largely due to the erroneous model representation of the underlying surface at these sites. An examination of the land-use categories used by the model indicates that all three island sites (AMI, MIN and POR) and the six coastal sites (BOM, GOA, PAN, COC, THI and VIS) are treated as "water bodies" by the model and the other four coastal sites (BHU, MAC, MAD and KAR) are treated as "Irrigated Cropland and Pasture". The differences between the true and the model topography may also contribute to errors in the model simulated temperature. The actual altitudes of the site along with the altitude used by the model are shown in the Table 1. The difference in the true and the model topography is less than $250 \mathrm{~m}$ for all the sites and is less than $50 \mathrm{~m}$ for 26 out of the 34 sites considered here.

The MB, RMSE, RMSE $\mathrm{s}_{\mathrm{s}}$ and $\mathrm{RMSE}_{\mathrm{u}}$ show a gradual increase in magnitude with altitude. For all the site categories, average values of $\mathrm{MB}, \mathrm{RMSE}, \mathrm{RMSE}_{\mathrm{s}}$ and $\mathrm{RMSE}_{\mathrm{u}}$ are lower for the temperature $(0.2-7 \mathrm{~K})$ compared to dew point temperature profiles $(0.1-10 \mathrm{~K})$.Systematic errors contribute more to RMSE between the model and in situ observations. Apart from the model, the errors in the radiosonde water vapor measurements due to reduced water vapor amount and slower 


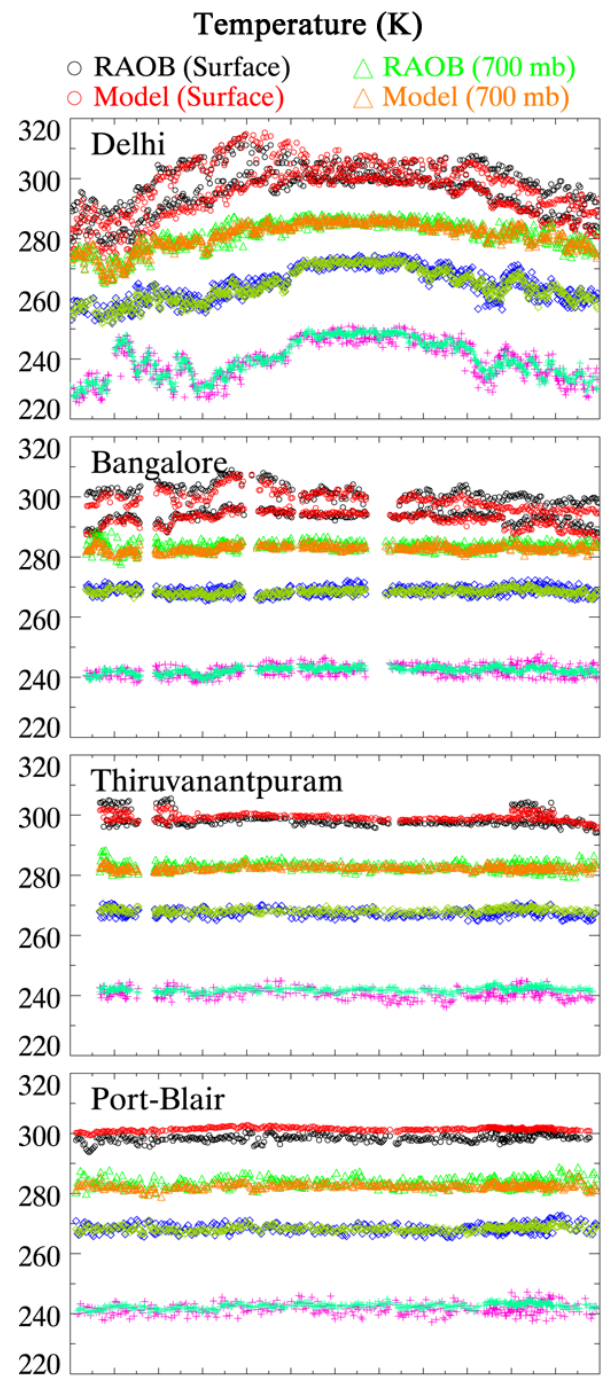

Ja Fe Ma Ap Ma Ju Ju Au Se Oc No De

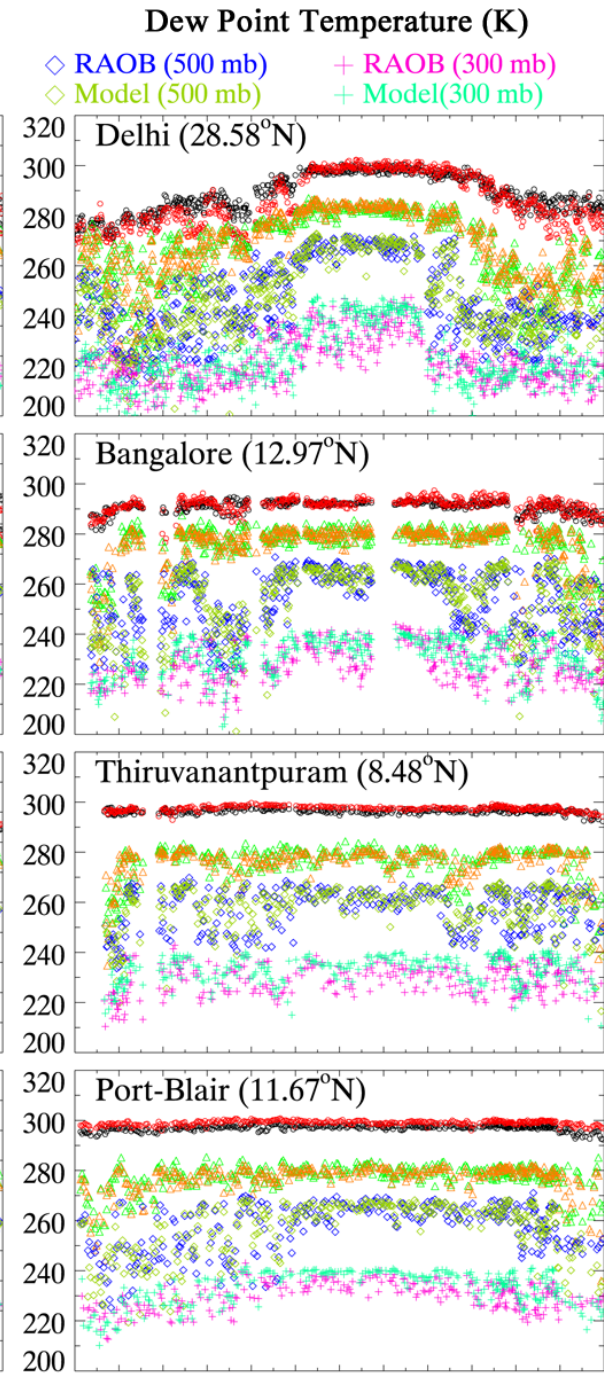

Ja Fe Ma Ap Ma Ju Ju Au Se Oc No De

Fig. 11. Seasonal variation of co-located observed and the model simulated temperature (left panels) and dew point temperature (right panels) at the surface, $700 \mathrm{hPa}, 500 \mathrm{hPa}$ and $300 \mathrm{hPa}$ for Delhi (low altitude), Bangalore (moderately high altitude), Thiruvanantpuram (coastal) and Port-Blair (island) during 2008.

response of the sensor to the ambient humidity at higher altitudes may also degrade the model-observation relationship particularly for the dew point temperature.

\subsection{Tropopause pressure (AIRS and radiosonde)}

The budget of trace species, in particular of ozone and water vapor, in the troposphere is affected through stratospheretroposphere exchange processes and therefore evaluation of the model simulated tropopause pressure is also important. Since the model output does not contain the tropopause pressure, we derive it following the method of Reichler et al. (2003). This method defines tropopause pressure as the lowest pressure level at which the lapse rate decreases to $2 \mathrm{~K} \mathrm{~km}^{-1}$ or less and the average lapse rate between this level and all higher levels within $2 \mathrm{~km}$ does not exceed $2 \mathrm{~K} \mathrm{~km}^{-1}$. This method is reported to calculate the tropopause pressure with small errors of $10-20 \mathrm{hPa}$ in the tropics and 30 $40 \mathrm{hPa}$ in the extratropics (Reichler et al., 2003). Here, the model simulated tropopause pressure is compared with that retrieved by AIRS and observed by the radiosonde (RAOB), both of which are estimated using the methodology of Reichler et al. (2003).

The spatial distributions of AIRS retrieved and model simulated tropopause pressure for winter, spring, summer and autumn are shown in Fig. 13. The spatial distribution of tropopause pressure as retrieved by AIRS is reasonably well simulated by the model during all seasons. The values of $r^{2}(>0.6)$ and index of agreement $(>0.9)$ between AIRS and model are high except during summer when there are 

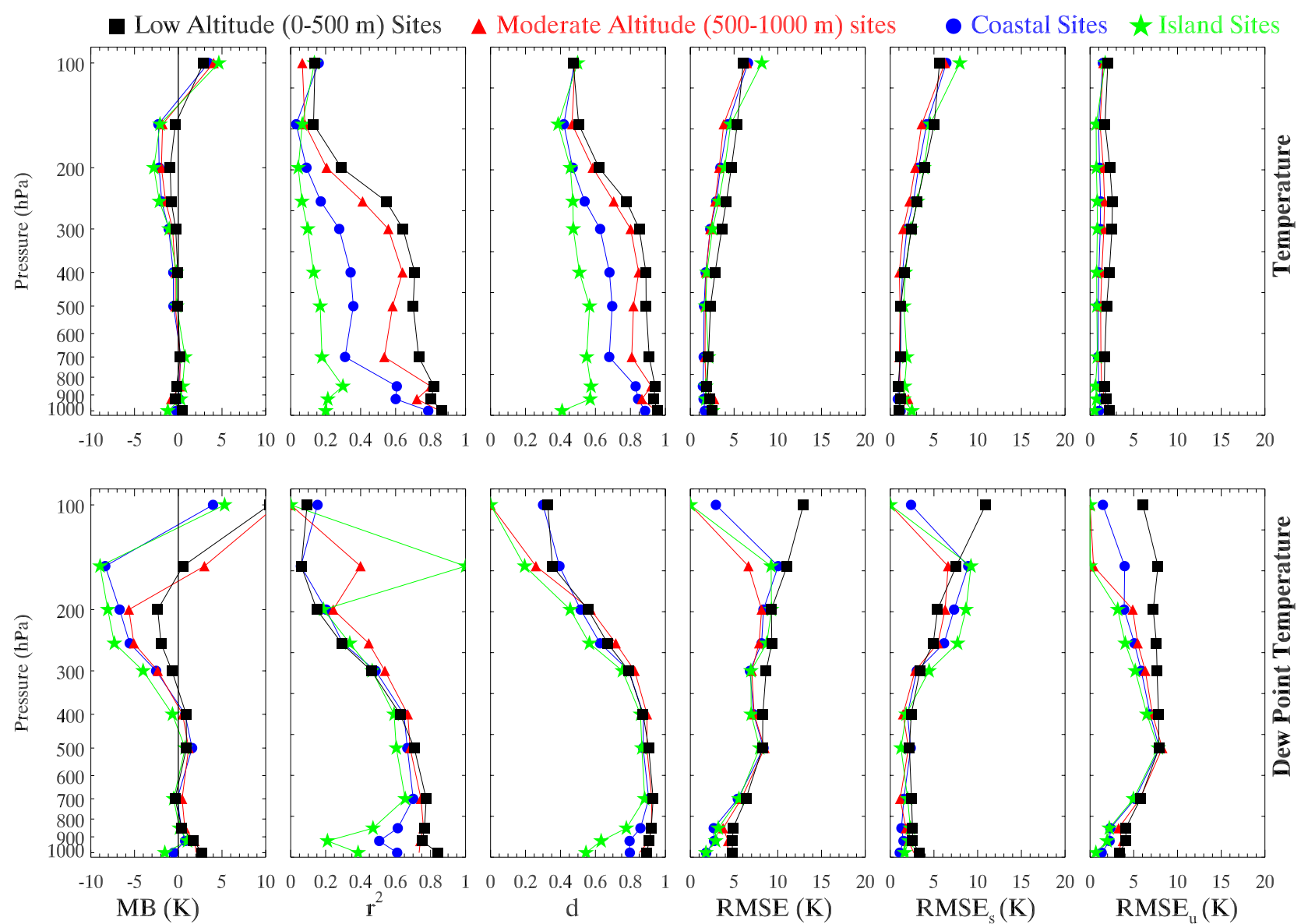

Fig. 12. Vertical profiles of the statistical metrics for temperature (top panel) and dew point temperature (bottom panel) at all the sites belonging to low altitude, moderate altitude, coastal and island sites. Average profiles of the statistical metrics for each site category are also shown. The dotted lines represent the profiles for individual sites and solid lines connected by symbols represent the respective average profiles.

fewer clear-sky observations and a smaller set of observations available. Both AIRS and model tropopause pressure show a distinct seasonal cycle with highest tropopause pressure in summer $(90-100 \mathrm{hPa})$ and lowest in winter $(120$ $270 \mathrm{hPa}$ ) over the regions located north of $30^{\circ} \mathrm{N}$ latitude belt. South of $30^{\circ} \mathrm{N}$ the seasonal amplitude is small (10-20 hPa). The latitudinal variation in tropopause pressure can be attributed to the seasonal variability in solar radiation at the sub-tropical latitudes.

The differences between AIRS and the model tropopause pressure can be discerned over the topographically complex Himalayan region. The mean bias values in the model simulated tropopause pressure as compared to the AIRS retrievals are estimated as $1 \mathrm{hPa},-9 \mathrm{hPa}, 2 \mathrm{hPa}$ and $5 \mathrm{hPa}$ for the four seasons, respectively and the corresponding RMSE values are 36, 36, 24 and $25 \mathrm{hPa}$, respectively. These differences over the Himalayan region could be attributed to the errors in the simulated temperature profiles associated with improper representation of surface topography in the model and the topography induced errors in the satellite retrievals.
Apart from evaluation with AIRS retrievals, the errors in WRF-Chem simulated tropopause pressure are also quantified by comparing the model results with RAOB datasets. The annual average values of the RAOB and the model estimated tropopause pressure values for the defined four site categories are shown in Table 8, which also shows the comparison of WRF-Chem and AIRS tropopause pressure for the four site categories. Mean WRF-Chem and AIRS tropopause pressure values are estimated by averaging the co-located data points over a $0.25^{\circ} \times 0.25^{\circ}$ box centered at the geographical location of a RAOB site. The annual average tropopause pressure values in WRF-Chem and AIRS are estimated to be around $98-103 \mathrm{hPa}$ as compared to the RAOB values of 115-120 hPa. The MB and RMSE in the model estimated tropopause pressure values with respect to the corresponding RAOB values are estimated to be 14$17 \mathrm{hPa}$ and $19-23 \mathrm{hPa}$ respectively (Table 8 ) while the respective values resulting from comparison with AIRS are -1 to $-3 \mathrm{hPa}$ and 3-22 $\mathrm{hPa}$ respectively. By having an accurately placed tropopause, stratosphere-troposphere exchange 

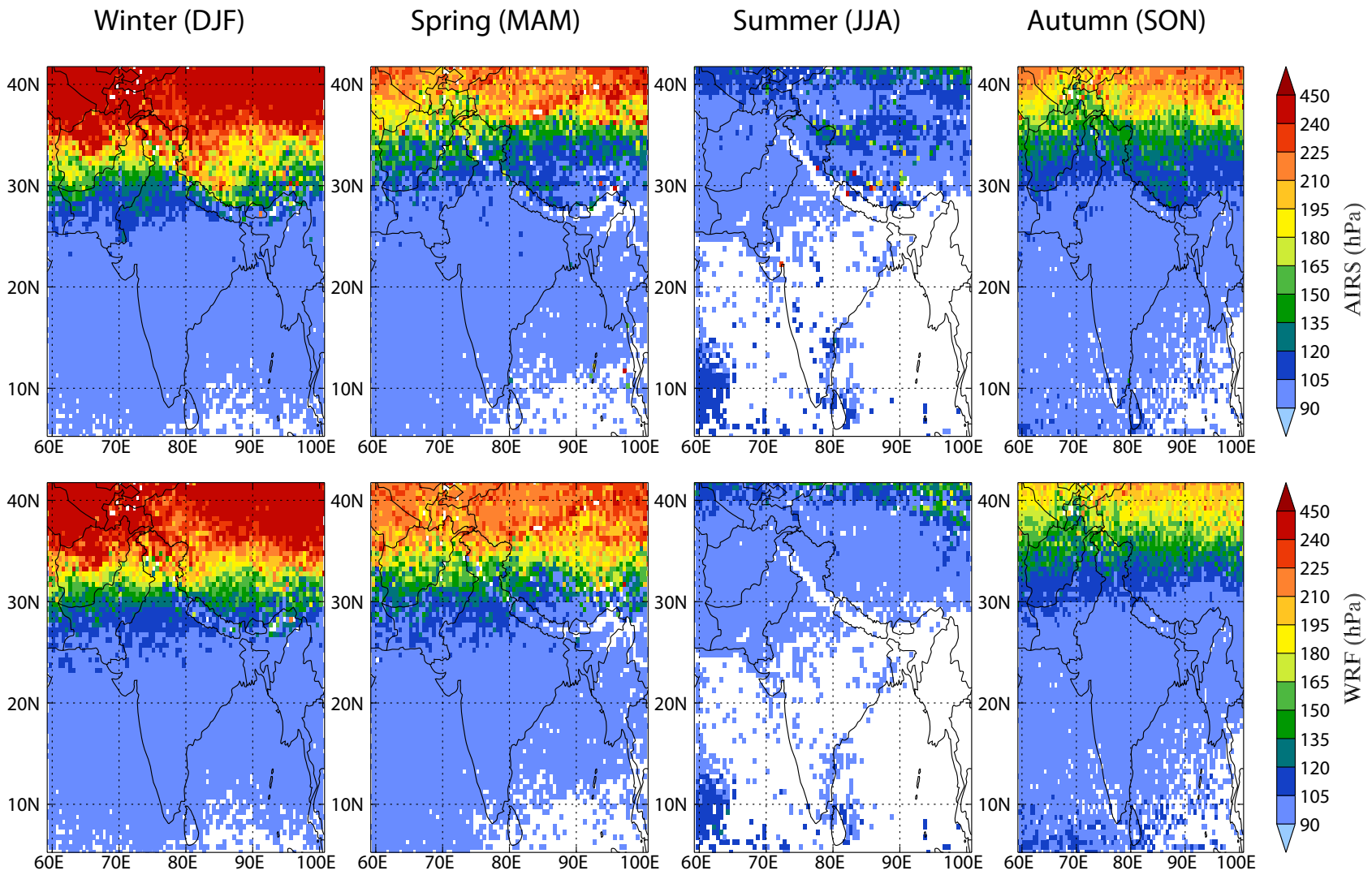

Fig. 13. Spatial distribution of co-located AIRS retrieved (top panel) and model simulated (bottom panel) tropopause pressure during the winter, spring, summer and autumn seasons of the year 2008.

Table 8. Annual average and standard deviation in co-located RAOB and WRF-Chem tropopause pressures for the four site categories defined in this study are shown along with mean bias and the root mean square error. All these statistical parameters are also shown for co-located AIRS and WRF-Chem tropopause pressure values. All the values are rounded off to their nearest integer values.

\begin{tabular}{|c|c|c|c|c|c|c|c|c|}
\hline \multirow{2}{*}{ Site Category } & \multicolumn{4}{|c|}{ WRF-Chem vs. RAOB Tropopause Pressure (hPa) } & \multicolumn{4}{|c|}{ WRF-Chem vs. AIRS Tropopause Pressure (hPa) } \\
\hline & RAOB & WRF-Chem & MB & RMSE & AIRS & WRF-Chem & MB & RMSE \\
\hline Low Altitude & $115 \pm 14$ & $101 \pm 8$ & 14 & 21 & $101 \pm 21$ & $103 \pm 18$ & -2 & 22 \\
\hline Moderately High Altitude & $115 \pm 12$ & $100 \pm 2$ & 15 & 19 & $98 \pm 4$ & $99 \pm 2$ & -2 & 4 \\
\hline Coastal & $118 \pm 13$ & $102 \pm 2$ & 16 & 21 & $100 \pm 18$ & $101 \pm 2$ & -1 & 18 \\
\hline Island & $120 \pm 15$ & $103 \pm 2$ & 17 & 23 & $99 \pm 2$ & $102 \pm 2$ & -3 & 3 \\
\hline
\end{tabular}

processes should be reasonably represented. This is particularly important for the Himalayan region.

\subsection{Sensitivity simulations}

The possible impacts of estimated errors in meteorological parameters on the simulations of chemical species concentrations were discussed qualitatively and individually for each parameter in the previous sections. This section presents the results from sensitivity simulations conducted to quantify the errors in chemistry simulations by combining the errors in meteorological parameters. The initial and boundary conditions for temperature, water vapor and wind components are modified by adding highest MB value, identified by comparing MB profiles of all the four seasons, of the respective meteorological parameter at each level between $1000 \mathrm{hPa}$ and $100 \mathrm{hPa}$ and 10-days runs are conducted during May and July (representing the months of dry and wet weather conditions). The MB profiles used for perturbation of meteorological parameters are shown in Table 9. It is to be noted that emissions of trace gases and aerosols are not changed from the base model run values for these sensitivity runs. The percentage 
Table 9. Vertical profiles of mean bias in temperature, water vapor and wind components used to modify the initial and boundary conditions of these meteorological variables between 1000 and $100 \mathrm{hPa}$ for sensitivity simulations. Note that mean bias profiles for water vapor are estimated only up to $300 \mathrm{hPa}$.

\begin{tabular}{rrrrr}
\hline $\begin{array}{r}\text { Pressure } \\
(\mathrm{hPa})\end{array}$ & $\begin{array}{r}\text { Temperature } \\
(\mathrm{K})\end{array}$ & $\begin{array}{r}\text { Water Vapor } \\
(\%)\end{array}$ & $\begin{array}{r}\text { Zonal Wind } \\
\left(\mathrm{m} \mathrm{s}^{-1}\right)\end{array}$ & $\begin{array}{r}\text { Meridional Wind } \\
\left(\mathrm{m} \mathrm{s}^{-1}\right)\end{array}$ \\
\hline 1000 & 1.4 & -6.7 & 0.23 & -0.40 \\
925 & -1.4 & 13.9 & 0.40 & 0.25 \\
850 & -0.4 & -17.1 & 0.57 & -0.47 \\
700 & -0.3 & -16.8 & 0.20 & -0.55 \\
600 & -0.8 & -5.7 & 0.31 & -0.70 \\
500 & -1.3 & -14.3 & 0.15 & -0.36 \\
400 & -0.8 & -15.0 & 0.27 & -0.05 \\
300 & -0.7 & -32.0 & 0.32 & 0.11 \\
250 & -1.2 & - & 0.34 & 0.27 \\
200 & -1.2 & - & 1.22 & 0.51 \\
150 & -1.5 & - & 1.64 & 0.54 \\
100 & -1.8 & - & 1.37 & 0.44 \\
\hline
\end{tabular}

differences in model simulated tropospheric column ozone, $\mathrm{CO}$ and $\mathrm{NO}_{\mathrm{x}}$ between sensitivity and base model runs are calculated for each grid point and are shown in Fig. 14. In general, the percentage differences in tropospheric column ozone and $\mathrm{CO}$ are within $\pm 10 \%$ while those in $\mathrm{NO}_{\mathrm{x}}$ are as high as $25 \%$ for some of the grid points. The largest differences in tropospheric column $\mathrm{NO}_{\mathrm{x}}$ are seen over parts of Indo-Gangetic Plain, southern tip of India and along the eastern Indian coast. Since these simulations do not include lightning- $\mathrm{NO}_{\mathrm{x}}$ parametrization, these differences cannot be attributed to lightning- $\mathrm{NO}_{\mathrm{x}}$ process.

In order to understand the reasons for larger differences in tropospheric $\mathrm{NO}_{\mathrm{x}}$ distributions, model simulated precipitation from sensitivity and base runs are analyzed along with spatial distributions of ozone, $\mathrm{CO}$ and $\mathrm{NO}_{\mathrm{x}}$ at four different pressure levels $(850 \mathrm{hPa}, 700 \mathrm{hPa}, 500 \mathrm{hPa}$ and $300 \mathrm{hPa})$. The spatial distributions of percentage differences in model simulated ozone, $\mathrm{CO}$ and $\mathrm{NO}_{\mathrm{x}}$ at 850 and $500 \mathrm{hPa}$ during May and July are shown in Fig. 15. Perturbation in meteorological parameters causes the percentage differences in ozone and $\mathrm{CO}$ within $\pm 20 \%$ at different pressure levels. It is found that perturbations in meteorological parameters increase $\mathrm{NO}_{\mathrm{x}}$ levels by more $60-100 \%$ in the lower atmosphere and decrease them by $0-40 \%$ in the middle and upper troposphere. Similar enhancement in the lower atmosphere and decrease in middle-upper troposphere is also observed for model simulated nitric acid $\left(\mathrm{HNO}_{3}\right)$ and formaldehyde $(\mathrm{HCHO})$ values. Analysis of modeled precipitation reveals that areas of enhanced $\mathrm{NO}_{\mathrm{x}}, \mathrm{HNO}_{3}$ and $\mathrm{HCHO}$ levels are associated with reduced precipitation. The reduction in precipitation results in a longer $\mathrm{HNO}_{3}$ lifetime allowing it to transform back to $\mathrm{NO}_{\mathrm{x}}$ via photolysis.

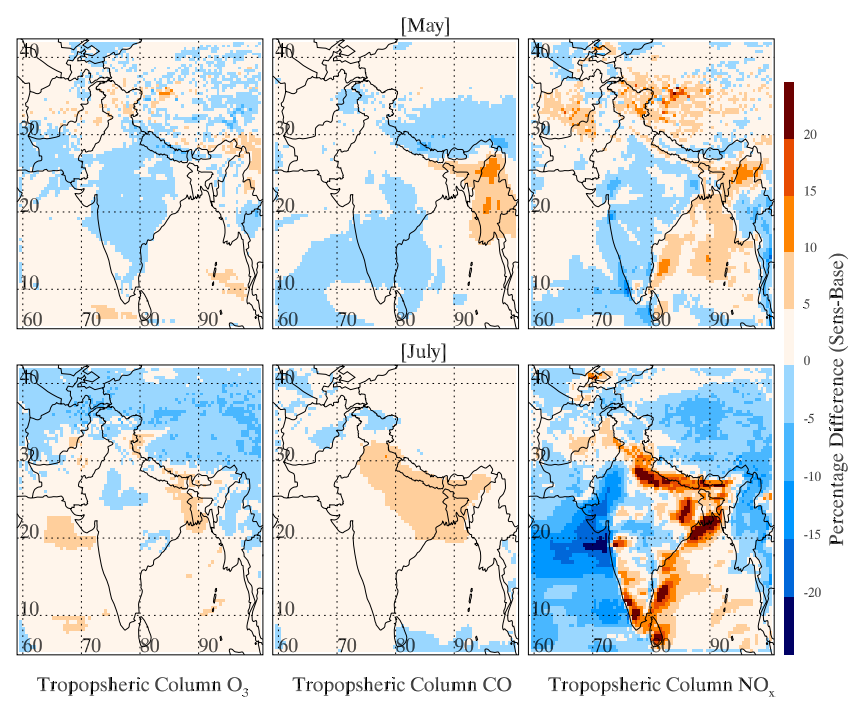

Fig. 14. Spatial distributions of percentage differences in model simulated tropospheric column ozone, $\mathrm{CO}$ and $\mathrm{NO}_{\mathrm{x}}$ between sensitivity and base model runs during May and July 2008.

\section{Summary and discussions}

The Weather Research and Forecasting model coupled with Chemistry (WRF-Chem) has been set-up over the South Asian region and has been used, for the first time, to simulate a full year (2008). In this manuscript, the meteorological parameters simulated by the model are evaluated through comparison with a variety of datasets including radiosonde observations of temperature, dew point temperature and tropopause pressure, AIRS retrievals of temperature, water vapor and tropopause pressure, NCEP reanalysis zonal and meridional wind components and TRMM derived daily 


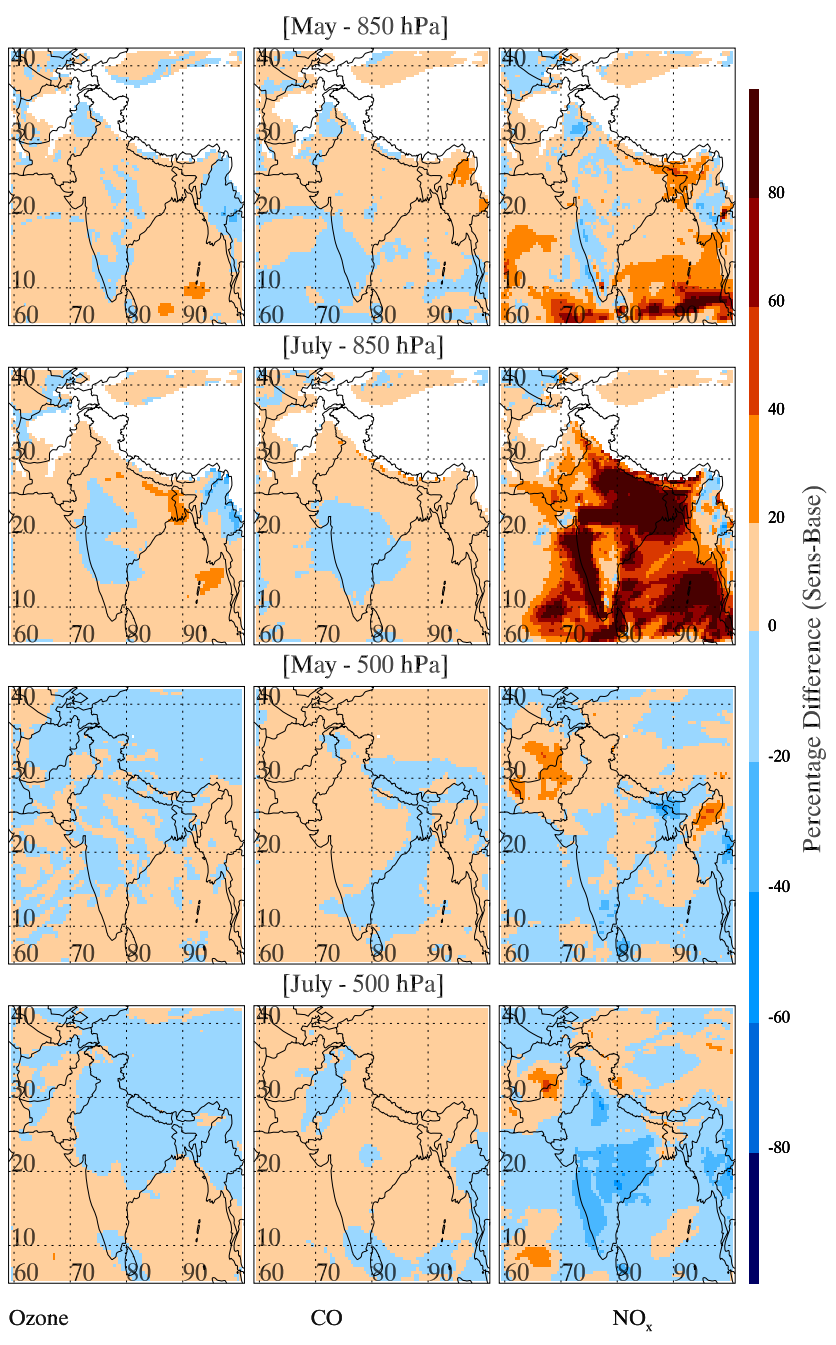

Fig. 15. Spatial distributions of percentage differences in ozone, $\mathrm{CO}$ and $\mathrm{NO}_{\mathrm{x}}$ at 850 and $500 \mathrm{hPa}$ between sensitivity and base model runs during May and July 2008. White space in the top two panels indicates the regions of surface pressure lower than $850 \mathrm{hPa}$.

precipitation. The model results are co-located in both space and time with the quality-controlled observed data for proper comparison. The model successfully replicated the general features of the South Asian meteorology such as the seasonal changes in wind patterns along with the seasonal cycle of temperature, water vapor, precipitation and tropopause pressure. All these meteorological parameters showed a distinct seasonal cycle with highest values (altitude in case of tropopause pressure) in summer and lowest during winter.

The model-observation relationship and the errors in the model simulated parameters are quantified using different statistical metrics. The statistics obtained by this comparison indicate that the agreement between model and observations is better for temperature as compared to the other parameters. The model is biased cold near the surface in all the seasons while it is biased warm aloft with MB and RMSE values within $\pm 2 \mathrm{~K}$ and $1-4 \mathrm{~K}$, respectively. Both $\mathrm{MB}$ and RMSE in temperature are estimated to be higher at the surface and lower at upper levels. On average, the model is biased dry at $1000 \mathrm{hPa}$ in winter and spring while it is biased wet at this level in summer and autumn with MB and RMSE values less than $20 \%$. The mean bias and RMSE in water vapor at upper pressure levels range between 20 $30 \%$ and $20-65 \%$, respectively. The model simulated winds show both an easterly and a northerly bias. RMSE in zonal and meridional wind components are estimated to be 2.3$5.1 \mathrm{~m} \mathrm{~s}^{-1}$ and 2.2-3.9 $\mathrm{m} \mathrm{s}^{-1}$, respectively. MB and RMSE in wind components increase gradually with altitude. The spatial and temporal variability of rainfall events is also captured reasonably well by the model as indicated by higher odd ratio values (6-92). The frequency bias index values indicate that the model generally overestimates domain-wide precipitation except for some events exceeding $40 \mathrm{~mm}_{\text {day }}{ }^{-1}$ in winter.

The radiosonde observations are classified into low altitude, moderately high altitude, coastal and island sites. The seasonal variability of temperature and dew point temperature for these four categories is replicated well by the model. However, estimated statistical metrics indicate relatively better result for inland sites as compared to coastal and island sites. Analysis of the topography and land-cover used by the model suggest that erroneous representation of these surface characteristics possibly due in parts to the coarse model resolution $(45 \mathrm{~km})$ leads to a poorer correlation for these sites. The spatio-temporal variability of tropopause pressure is also simulated well by the model with mean bias and RMSE values less than $25 \mathrm{hPa}$.

The statistical metrics estimated for temperature, water vapor and wind components are also compared with a set of proposed benchmarks to assess the implications of errors in these parameters for chemistry simulations. In general, the errors in model simulated meteorological parameters are well within or comparable to the proposed benchmark values and comparison with other studies showed that the errors in these parameters should induce only small errors in chemistry simulations. The errors in simulations of tropospheric ozone, $\mathrm{CO}$ and $\mathrm{NO}_{\mathrm{x}}$ due to biases in simulations of temperature, water vapor and wind components are estimated to be within $\pm(10-25 \%)$. Overall, the model has good ability to simulate the spatio-temporal variabilities of meteorological parameters over this region and would be of sufficient quality for use in chemical transport modeling.

Acknowledgements. M. Naja and R. Kumar are thankful to Shyam Lal, Ram Sagar and C. B. S. Dutt for their keen interest in this work and acknowledge support from ISROATCTM project. The meteorological datasets for initial and boundary conditions are downloaded from the website http://dss.ucar.edu/datasets/ds083.2/data/. Radiosonde data are retrieved from the website http://www.esrl.noaa.gov/raobs/. NCEP/NCAR reanalysis datasets are downloaded from their website at http://www.esrl.noaa.gov/. The National Center for 
Atmospheric Research is supported by the National Science Foundation. We are thankful to the reviewers for their constructive comments.

Edited by: R. Sander

\section{References}

Ackermann, I. J., Hass, H., Memmesheimer, M., Ebel, A., Binkowski, F. S., and Shankar, U.: Modal aerosol dynamics model for Europe: development and first applications, Atmos. Environ., 32, 2981-2999, 1998.

Adler, R. F., Huffman, G. J., Bolvin, D. T., Curtis, S., and Delkin, E. J.: Tropical Rainfall Distributions Determined using TRMM Combined with Other Satellite and Rain Guage Information, J. Appl. Meteorol., 39, 2007-2023, 2000.

Akimoto, H.: Global air quality and pollution, Science, 302, 17161719, doi:10.1126/science.1092666, 2003.

Asnani, G. C.: Climatology of the tropics, in: Tropical Meteorology, Vol. 1, 100-204, 2005.

Aumann, H. H., Chahine, M. T., Gautier, C., Goldberg, M. D., Kalnay, E., McMillin, L. M., Revercomb, H., Rosenkranz, P. W., Smith, W. L., Staelin, D. H., Strow, L. L., and Susskind, J. : AIRS/AMSU/HSB on the Aqua mission: Design, science objectives, data products, and processing systems, IEEE Trans. Geosci. Remote Sens., 41, 253-264, 2003.

Babu, S. S., Satheesh, S. K., and Moorthy, K. K.: Aerosol radiative forcing due to enhanced black carbon at an urban site in India, Geophys. Res. Lett., 29, 1880, doi:10.1029/2002GL015826, 2002.

Bao, J.-W., Michelson, S. A., McKeen, S. A., and Grell, G. A.: Meteorological evaluation of a weather-chemistry forecasting model using observations from the TEXAS AQS 2000 field experiment, J. Geophys. Res., 110, D21105, doi:10.1029/2004JD005024, 2005.

Beig, G. and Brasseur, G. P.: Influence of anthropogenic emissions on tropospheric ozone and its precursors over the Indian tropical region during a monsoon, Geophys. Res. Lett., 33, L07808, doi:10.1029/2005GL024949, 2006.

Chang, H.-I., Niyogi, D., Kumar, A., Kishtawal, C. M., Dudhia, J, Chen, F., Mohanty, U. C., and Shepherd, M.: Possible relation between land surface feedback and post-landfall structure of monsoon depressions, Geophys. Res. Lett., 36, L15826, doi:10.1029/2009GL037781, 2009.

Chen, F. and Dudhia, J.: Coupling and advanced land surfacehydrology model with the Penn State-NCAR MM5 modeling system, Part I: Model implementation and sensitivity, Mon. Weather Rev., 129, 569-585, 2001.

Chou, M.-D. and Suarez, M. J.: An efficient thermal infrared radiation parametrization for use in general circulation models, NASA Tech. Memo. 104606, 3, 85 pp., 1994.

Courant, R., Friedrichs, K., and Lewy, H.: Über die partiellen Differenzengleichungen der mathematischen Physik, Math. Ann., 100, 32-74, 1928.

de Meij, A., Gzella, A., Cuvelier, C., Thunis, P., Bessagnet, B., Vinuesa, J. F., Menut, L., and Kelder, H. M.: The impact of MM5 and WRF meteorology over complex terrain on CHIMERE model calculations, Atmos. Chem. Phys., 9, 66116632, doi:10.5194/acp-9-6611-2009, 2009.
Divakarla, M. G., Barnet, C. D., Goldberg, M. D., McMillin, L. M., Maddy, E., Wolf, W., Zhou, L., and Liu, X.: Validation of Atmospheric Infrared Sounder temperature and water vapor retrievals with matched radiosonde measurements and forecast, J. Geophys. Res., 111, D09S15, doi:10.1029/2005JD006116, 2006.

Dutta, S. K. and Prasad, V. S.: Assessment of WRF-VAR assimilation for a cyclonic storm-Nisha, Curr. Sci., 99, 86-91, 2010.

Emery, C. A.: Enhanced meteorological modeling and performance evaluation for two Texas ozone episodes, Prepared for the Texas Natural Resource Conservation Commission, by ENVIRON International Corporation, 2001.

Engardt, M.: Modelling of near-surface ozone over South Asia, J. Atmos. Chem., 59, 61-80, doi:10.1007/s10874-008-9096-z, 2008.

Gettelman, A., Weinstock, E. M., Fetzer, E. J., Irion, F. W., Eldering, A., Richard, E. C., Rosenlof, K. H., Thompson, T. L., Pittman, C., Webster, R., and Herman, R. L.: Validation of Aqua satellite data in the upper troposphere and lower stratosphere with in situ aircraft measurements, Geophys. Res. Lett., 31, L22107, doi:10.1029/2004GL020730, 2004.

Grell, G. A., Peckham, S. E., Schmitz, R., McKeen, S. A., Frost, G., Skamarock, W. C., and Eder, B.: Fully coupled "online" chemistry within the WRF model, Atmos. Environ., 39, 6957-6975, 2005.

Hashiguchi, N. O., Yamanaka, M. D., Ogino, S.-Y., Shiotani, M., and Sribimawati, T.: Seasonal and interannual variations of temperature in the tropical tropopause layer (TTL) over Indonesia based on operational rawinsonde data during 1992-1999, J. Geophys. Res., 111, D15110, doi:10.1029/2005JD006501, 2006.

Hu, X.-M., Gammon, J. W. N., and Zhang, F.: Evaluation of Three Planetary Boundary Layer Schemes in the WRF model, J. Appl. Meteor., 49, 1831-1844, 2010.

Jain, S. L., Arya, B. C., Kumar, A., Ghude, S. D., and Kulkarni, P. S.: Observational study of surface ozone at New Delhi, India, Int. J. Remote Sens., 26, 3515-3524, 2005.

Janjic, Z. I.: The surface layer in the NCEP Eta Model, Eleventh Conference on Numerical Weather Prediction, Norfolk, VA, 1923 August, Amer. Meteor. Soc., Boston, Boston, MA, 354-355, 1996.

Janjic, Z. I.: Nonsingular Implementation of the Mellor-Yamada Level 2.5 Scheme in the NCEP Meso model, NCEP Office Note, 437, 61 pp., 2002.

Kain, J. S.: The Kain-Fritsch convective parameterization: An update, J. Appl. Meteor., 43, 170-181, 2004.

Kalnay, E., Kanamitsu, M., Kistler, R., Collins, W., Deaven, D., Gandin, L., Iredell, M., Saha, S., White, G., Woollen, J., Zhu, Y., Chelliah, M., Ebisuzaki, W., Higgins, W., Janowiak, J., Mo, K. C., Ropelewski, C., Wang, J., Leetmaa, A., Reynolds, R., Jene, R., and Joseph, D.: The NCEP/NCAR 40-year reanalysis project, Bull. Am. Meteorol. Soc., 77, 437-471, 1996.

Kistler, R., Kalnay, E., Collins, W., Saha, S., White, G., Woollen, J., Chelliah, M., Ebisuzaki, W., Kanamitsu, M., Kousky, V., van den Dool, H., Roy, J., and Fiorino, M.: The NCEP-NCAR 50year Reanalysis: Monthly means CD-ROM and documentation, Bull. Am. Meteorol. Soc., 82, 247-267, 2001.

Kumar, R., Naja, M., Pfister, G. G., Barth, M. C., Wiedinmyer, C., and Brasseur, G. P.: Simulations over South Asia using the weather research and forecasting model with chemistry (WRFChem): chemistry evaluation and initial results, Geosci. Model 
Dev. Discuss., 5, 1-66, doi:10.5194/gmdd-5-1-2012, 2012

Lal, S., Naja, M., and Subbaraya, B. H.: Seasonal variations in surface ozone and its precursors over an urban site in India, Atmos. Environ., 34, 2713-2724, 2000.

Lawrence, M. G. and Lelieveld, J.: Atmospheric pollutant outflow from southern Asia: a review, Atmos. Chem. Phys., 10, 1101711096, doi:10.5194/acp-10-11017-2010, 2010.

Lelieveld, J., Crutzen, P. J., Ramanathan, V., Andreae, M. O., Brenninkmeijer, C. A. M., Campos, T., Cass, G. R., Dickerson, R. R., Fischer, H., de Gouw, J. A., Hansel, A., Jefferson, A., Kley, D., de Laat, A. T. J., Lal, S., Lawrence, M. G., Lobert, J. M., MayolBracero, O. L., Mitra, A. P., Novakov, T., Oltmans, S. J., Prather, K. A., Reiner, T. A., Rodhe, H., Scheeren, H. A., Sikka, D., and Williams, J.: The Indian Ocean Experiment: Widespread Air Pollution From South and Southeast Asia, Science, 291, 10311036, 2001.

Lo, J. C.-F., Yang, Z.-L., and Pielke Sr., R. A.: Assessment of three dynamical climate downscaling methods using the Weather Research and Forecasting (WRF) model, J. Geophys. Res., 113, D09112, doi:10.1029/2007JD009216, 2008.

Matsui, H., Koike, M., Kondo, Y., Takegawa, N., Kita, K., Miyazaki, Y., Hu, M., Chang, S.-Y., Blake, D. R., Fast, J. D., Zaveri, R. A., Streets, D. G., Zhang, Q., and Zhu, T.: Spatial and temporal variations of aerosols around Beijing in summer 2006: Model Evaluation and source apportionment, J. Geophys. Res., 114, D00G13, doi:10.1029/2008JD010906, 2009.

McKeen, S., Wilczak, J., Grell, G., Djalalova, I., Peckham, S., Hsie, E.-Y., Gong, W., Bouchet, V., Menard, S., Moffet, R., McHenry, J., McQueen, J., Tang, Y., Carmichael, G. R., Pagowski, M., Chan, A., Dye, T., Frost, G., Lee, P., Mathur, R.: Assessment of an ensemble of seven real-time ozone forecasts over Eastern North America during the summer of 2004, J. Geophys. Res., 110, D21307, doi:10.1029/2005JD005858, 2005.

Minguzzi, E., Bedogni, M., Carnevale, C., and Pirovano, G.: Sensitivity of CTM simulations to meteorological input, Int. J. Environ. Pollut., 24, 36-50, 2005.

Mlawer, E. J., Taubman, S., Brown, P., Iacono, M., and Clough, S.: Radiative transfer for inhomogenous atmosphere: RRTM, a validated correlated-k model for the lon-wave, J. Geophys. Res., 102, D14, doi:10.1029/97JD00237, 1997.

Moorthy, K. K., Sathessh, S. K., Babu, S. S., and Dutt, C. B. S.: Integrated Campaign for Aerosols, Gases and Radiation Budget (ICARB): An overview, J. Earth. Syst. Sci., 117, 243-262, 2008.

Nair, S., Srinivasan, G., and Nemani, R.: Evaluation of MultiSatellite TRMM Derived Rainfall Estimates over a Western State of India, J. Meteorol. Soc. Jpn., 87, 927-939, doi:10.2151/jmsj.87.927, 2009.

Naja, M. and Lal, S.: Surface ozone and precursor gases at Gadanki $\left(13.5^{\circ} \mathrm{N}, 79.2^{\circ} \mathrm{E}\right)$, tropical rural site in India, J. Geophys. Res., 107, ACH 8-1 to ACH 8-13, doi:10.1029/2001JD000357, 2002.

Nenes, A., Pilinis, C., and Pandis, S. N.: ISOROPIA: a new thermodynamic model for inorganic multicomponent atmospheric aerosols, Aquat. Geochem., 4, 123-152, 1998.

Niranjan, K., Sreekanth, V., Madhavan, B. L., and Krishna Moorthy, K.: Wintertime aerosol characteristics at a north Indian site Kharagpur in the Indo-Gangetic plains located at the outflow region into Bay of Bengal, J. Geophys. Res., 111, D24209, doi:10.1029/2006JD007635, 2006.

Ohara, T., Akimoto, H., Kurokawa, J., Horii, N., Yamaji, K.,
Yan, X., and Hayasaka, T.: An Asian emission inventory of anthropogenic emission sources for the period 1980-2020, Atmos. Chem. Phys., 7, 4419-4444, doi:10.5194/acp-7-4419-2007, 2007.

Olsen, T. E., Fishbein, E., Hearty, T., Lee, S.-Y., Irion, F. W., Kahn, B., Manning, E., Blaisdell, J., Susskind, J., Iredell, L., Barnet, C., Maddy, E., Rosenkranz, P., McMillan, W. W., Machado, S. D., and Knuteson, R.: AIRS Version 5 Release Level 2 Standard Product Quickstart, available at: http://airs.jpl.nasa.gov/, 2007.

Rajeevan, M., Kesarkar, A., Thampi, S. B., Rao, T. N., Radhakrishna, B., and Rajasekhar, M.: Sensitivity of WRF cloud microphysics to simulations of a severe thunderstorm event over Southeast India, Ann. Geophys., 28, 603-619, doi:10.5194/angeo-28603-2010, 2010.

Rakesh, V., Singh, R., and Joshi, P. C.: Intercomparison of the performance of MM5/WRF with and without satellite data assimilation in short-range forecast applications over the Indian region. Meteorol. Atmos. Phys., 105, 133-155, doi:10.1007/s00703009-0038-3, 2009.

Ramanathan, V. and Crutzen, P. J.: New Directions: Atmospheric Brown "Clouds", Atmos. Environ., 37, 4033-4035, 2003.

Ramanathan, V., Crutzen, P. J., Lelieveld, J., Mitra, A. P., Althausen, D., Anderson, J., Andreae, M. O., Cantrell, W., Cass, G. R., Chung, C. E., Clarke, A. D., Coakley, J. A., Collins, W. D., Conant, W. C., Dulac, F., Heintzenberg, J., Heymsfield, A. J., Holben, B., Howell, S., Hudson, J., Jayaraman, A., Kiehl, J. T., Krishnamurti, T. N., Lubin, D., McFarquhar, G., Novakov, T., Ogren, J. A., Podgorny, I. A., Prather K., Priestley, K., Prospero, J. M., Quinn, P. K., Rajeev, K., Rasch, P., Rupert, S., Sadourny, R., Satheesh, S. K., Shaw, G. E., Sheridan, P., and Valero, F. P. J.: Indian Ocean Experiment: An integrated analysis of the climate forcing and effects of great Indio-Asian haze, J. Geophys. Res., 106, 28371-28398, 2001.

Rao, V., Chapa, S., and Cavalcanti, I.: Moisture budget in the tropics and the Walker circulation, J. Geophys. Res., 103, D12, doi:10.1029/98JD00943, 1998.

Ratnam, V. J. and Kumar, K. K.: Sensitivity of the simulated monsoon of 1987 and 1988 to convective parameterization schemes in MM5, J. Climate, 18, 2724-2743, 2005.

Reichler, T., Dameris, M., and Sausen, R.: Determining the tropopause height from gridded data, Geophys. Res. Lett., 30, 2042, doi:10.1029/2003GL018240, 2003.

Remsberg, E., Bhatt, P., and Miles, T.: A Comparison of Nimbus 7 Limb Infrared Monitor of the Stratosphere and Radiosonde Temperatures in the Lower Stratosphere Pole ward of 60 N, J. Geophys. Res., 97, D12, doi:10.1029/92JD01012, 1992.

Roy, S., Beig, G., and Jacob, D.: Seasonal distribution of ozone and its precursors over the tropical Indian region using regional chemistry-transport model, J. Geophys. Res., 113, D21307, doi:10.1029/2007JD009712, 2008.

Sagar, R., Kumar, B., Dumka, U. C., Krishna Moorthy, K., and Pant, P. Characteristics of aerosol optical depths over Manora Peak: A high altitude station in the central Himalayas, J. Geophys. Res., 109, D06207, doi:10.1029/2003JD003954, 2004.

Sathessh, S. K., Moorthy, K. K., Babu, S. S., Vinoj, V., and Dutt, C. B. S.: Climatic implications of large warming by elevated aerosols over India, Geophys. Res. Lett., 35, L19809, doi:10.1029/2008GL034944, 2008.

Schell, B., Ackermann, I. J., Hass, H., Binkowski, F. S., and Ebel, 
A.: Modeling the formation of secondary organic aerosol within a comprehensive air quality model system, J. Geophys. Res., 106, 28275-28293, 2001.

Schürmann, G. J., Algieri, A., Hedgecock, I. M., Manna, G., Pirrone, N., and Sprovieri, F.: Modeling local and synoptic scale influences on ozone concentrations in a topographically complex region of Southern Italy, Atmos. Environ., 43, 4424-4434, 2009.

Schwartz, B. and Govett, M.: A Hydrostatically Consistent North American Radiosonde Data base at the forecast System Laboratory, 1946-Present, NOAA Tech. Memorandum, ERL, FSL-4, Boulder, Colorado, 1992.

Skamarock, W. C., Klemp, J. B., Dudhia, J., Gill, D. O., Barker, D. M., Duda, M. G., Huang, X.-Y., Wang, W., and Powers, J. G.: A description of the advanced research WRF version 3, NCAR Tech. Note NCAR/TN-475+STR, Natl. Cent. for Atmos. Res., Boulder, Colo, 125 pp., 2008.

Stephenson, D. B.: Use of the "odd ratios" for diagnosticing forecast skill, Weather Forecast., 15, 221-232, 2000.
Thompson, G., Rasmussen, R. M., and Manning, K.: Explicit forecasts of winter precipitation using an improved bulk microphysics scheme, Part I: Description and sensitivity analysis, Mon. Weather Rev., 132, 519-542, 2004.

Tie, X., Madronich, S., Li, G., Ying, Z., Zhang, R., Garcia, A., LeeTaylor, J., and Liu, Y.: Characterization of chemical oxidants in Mexico City: A regional chemical dynamical model (WRFCHEM) study, Atmos. Environ., 41, 1989-2008, 2007.

Vieno, M., Dore, A. J., Stevenson, D. S., Doherty, R., Heal, M. R., Reis, S., Hallsworth, S., Tarrason, L., Wind, P., Fowler, D., Simpson, D., and Sutton, M. A.: Modelling surface ozone during the 2003 heat-wave in the UK, Atmos. Chem. Phys., 10, 79637978, doi:10.5194/acp-10-7963-2010, 2010.

Willmott, C. J.: On the validation of models, Phys. Geogr., 2, 184194, 1981. 